\title{
Coping with drought: stress and adaptive responses in potato and perspectives for improvement
}

\author{
Jude E. Obidiegwu ${ }^{1 \dagger}$, Glenn J. Bryan ${ }^{1}$, Hamlyn G. Jones ${ }^{2,3}$ and Ankush Prashar ${ }^{1 *}$ \\ ${ }^{1}$ Cell and Molecular Sciences, The James Hutton Institute, Dundee, UK, ${ }^{2}$ Plant Science Division, School of Life Sciences, \\ University of Dundee, Dundee, UK, ${ }^{3}$ School of Plant Biology, University of Western Australia, Crawley, WA, Australia
}

\section{OPEN ACCESS}

Edited by:

Susana Araújo,

Universidade Nova de Lisboa,

Portugal

Reviewed by:

Urs Feller,

University of Bern, Switzerland

Marcello Mastrorilli,

Consiglio per la ricerca in agricoltura e

l'analisi dell'economia agraria, Italy

*Correspondence:

Ankush Prashar,

Cell and Molecular Sciences, The James Hutton Institute, Errol Road, Invergowrie, Dundee DD2 5DA, UK ankush.prashar@hutton.ac.uk

${ }^{\dagger}$ Present Address:

Jude E. Obidiegwu, National Root Crops Research Institute Umudike, PMB 7006

Umuahia, Abia State, Nigeria

Specialty section:

This article was submitted to

Crop Science and Horticulture,

a section of the journal

Frontiers in Plant Science

Received: 07 May 2015

Accepted: 03 July 2015

Published: 22 July 2015

Citation:

Obidiegwu JE, Bryan GJ, Jones HG and Prashar A (2015) Coping with

drought: stress and adaptive

responses in potato and perspectives for improvement.

Front. Plant Sci. 6:542.

doi: 10.3389/fpls.2015.00542
Potato (Solanum tuberosum L.) is often considered as a drought sensitive crop and its sustainable production is threatened due to frequent drought episodes. There has been much research aiming to understand the physiological, biochemical, and genetic basis of drought tolerance in potato as a basis for improving production under drought conditions. The complex phenotypic response of potato plants to drought is conditioned by the interactive effects of the plant's genotypic potential, developmental stage, and environment. Effective crop improvement for drought tolerance will require the pyramiding of many disparate characters, with different combinations being appropriate for different growing environments. An understanding of the interaction between below ground water uptake by the roots and above ground water loss from the shoot system is essential. The development of high throughput precision phenotyping platforms is providing an exciting new tool for precision screening, which, with the incorporation of innovative screening strategies, can aid the selection and pyramiding of drought-related genes appropriate for specific environments. Outcomes from genomics, proteomics, metabolomics, and bioengineering advances will undoubtedly compliment conventional breeding strategies and presents an alternative route toward development of drought tolerant potatoes. This review presents an overview of past research activity, highlighting recent advances with examples from other crops and suggesting future research directions.

Keywords: potato, drought, yield, high throughput phenotyping, water use efficiency, breeding

\section{Introduction}

Potato (Solanum tuberosum L.) is of great economic value and ranks as the fourth most important food crop in the world. According to FAO (2011) global cultivation on 19.2 million hectares resulted in an estimated 374 million tons production. Potato production provides food, employment, and income as a cash crop (Scott et al., 2000) and helps in increasing food availability while contributing to a better land use ratio by raising the aggregate efficiency of agricultural production systems (Gastelo et al., 2014). Potatoes are grown in over 125 countries and more than a billion people worldwide consume them on a daily basis (Mullins et al., 2006). The poor and most undernourished farm households in many developing countries depend on potatoes as a primary or secondary source of food and nutrition (Lutaladio and Castaidi, 2009) as its short and flexible vegetative cycle makes it well suited for crop rotation with other major crops. Moreover, it can be cultivated in environmental conditions where other crops may fail 
(Food and Agriculture Organization of the United Nations, 2009). Global geographical production of potatoes shows that it is grown in all continents except Antarctica (Rowe and Powelson, 2002). Along with its flexibility for cultivation, potato also represents an excellent source of nutrients including carbohydrates, proteins, vitamin C, several forms of vitamin B, and minerals (Camire et al., 2009; White et al., 2009; Birch et al., 2012). As a major staple food, potato tubers are high in compounds including ascorbate, $\beta$-carotene, organic acids, and cysteine-rich polypeptides that promote mineral bioavailability. Furthermore, potato is low in anti-nutrients such as oxalates and phytates which can decrease mineral bioavailability (White et al., 2009).

Drought already poses one of the most important constraints to plant growth and terrestrial ecosystem productivity in many regions all over the world (Chaves et al., 2003) and water availability is becoming even scarcer for agricultural communities. The influencing factors include inadequate rainfall, excessive levels of salts in the soil solution or the increasing diversion of limited fresh-water resources to competing urban and industrial uses (Neumann, 2008). Climatic model predict that global warming will further escalate drought as a result of increasing evapotranspiration (Salinger et al., 2005; Cook et al., 2007) though there are likely to be large regional differences (Metz et al., 2007) with frequency and intensity increasing from 1 to $30 \%$ in extreme drought land area by 2100 (Fischlin et al., 2007). These negative consequences of climate change in agriculture will drastically affect poor and marginalized groups who depend on agriculture for their livelihoods coupled with limited potentials to cope. Impact of climate change on potato production in Ireland using simulation models (in the DSSAT package) showed an expected relatively uniform increase in temperature of about $1.6^{\circ} \mathrm{C}$ over the country by the 2075 climate period (Holden et al., 2003) and potato yield in 2055 and 2075 is expected to fall for non- irrigated tubers resulting in severe loss of yield over most of the country by 2055 (Holden et al., 2003). In northern temperate regions there will be more heterogeneity in weather events with northern Europe influencing more rain in winter and significantly less in summer (Haverkort and Verhagen, 2008) affecting both agriculture production and adaptation. In the Mediterranean and Sahel regions during the heat- free periods of the year potato yields will go down as the suitable periods become shorter. Higher evaporative demand will result to water being use less efficiently and only irrigation may hold the keys for yield increments in potato in the temperate (Haverkort and Verhagen, 2008). Globally, for potato, drought will decrease potential potato yield by $18-32 \%$ in the projected period of 2040-2069 (Hijmans, 2003). The indication for the effect of drought on potato production and cultivation can be seen from available FAO data and recent case studies. In 2011 and 2012 drought and heat waves in the USA have resulted in damage to summer crops (including potatoes) and livestock causing losses of \$40-88 in billions of dollars (NOAA, 2011, 2012) . In 2010, drought affected Russia and led to production losses of around $30 \%$ on industrial potato farms and households in the Central and the Volga Valley-a federal district that traditionally produces over $60 \%$ of the Russian potato crop
(GAIN, 2010; Barriopedro et al., 2011). Crop models predict that potato yields may reduce by $\sim 30 \%$ as a result of water deficit in Poland (http://www.climateadaptation.eu/poland/agricultureand-horticulture/).

\section{Drought Response}

\section{Drought Sensing and Signaling}

Drought limits productivity of crop plants by affecting photosynthetic processes at the canopy, leaf or chloroplast level, either directly, or by feedback inhibition if transport of photosynthate to sink organs is limited (Jones and Corlett, 1992). The response pattern of plants to drought is regulated by intensity, duration and rate of progression of imposed drought (Pinheiro and Chaves, 2011). Figure 1 provides an overview of the effect of different levels of drought and the response triggered under these levels. Under mild to moderate conditions, stomatal characteristics are affected which result in biomass loss while under severe conditions non-stomatal factors can become dominant (Liu et al., 2010) constraining photochemical efficiency and Rubisco activity and thus affecting the biochemical and physiological metabolisms (Xu et al., 2010). Light signal transduction pathway of guard cells remains the primary mechanism regulating stomatal opening (Lee, 2010), while mechanism of stomatal behavior is influenced by ABA in the root-to-shoot signaling under stress (Jia and Zhang, 2008). Plants grown under drought conditions tend to have lower stomatal conductance, thus helping to conserve water and maintain an adequate leaf water status but at the same time reducing leaf internal $\mathrm{CO}_{2}$ concentration and photosynthesis (Chaves et al., 2002). Nevertheless, the precise relationship is also dependent on other factors, for example genotype, influence of drought history, and environmental conditions (Schulze and Hall, 1982; Tardieu and Simonneau, 1998). It has been shown that long term exposure of leaf or canopy to low vapor pressure deficit generates a sort of "memory" in guard cells that results in loss of closing stimuli of stomatal responses (Nejad and Van Meeteren, 2007; Fanourakis et al., 2011). Thus, when studying drought response, differentiation is needed between terminal or intermittent drought and its interaction with environment. In the case of terminal drought the availability of soil water decreases progressively leading to premature plant death while intermittent drought comprises finite periods of inadequate water occurring at one or more intervals during the growing season (Neumann, 2008) (Figure 1). The timing of intermittent drought during growth may have much larger impact on biomass and yield than intensity of drought and may also depend on stress duration and phenological stage (Pinheiro and Chaves, 2011). Yield losses depend on plant growth phase affected by drought (vegetative and reproductive) (Serraj et al., 2004), which indirectly reduces the photosynthetic rate, $\mathrm{CO}_{2}$ fixation and finally resulting in less assimilate product (Mafakheri et al., 2010). Figure 2 details different growth stages in potato and how water limited environment can influence plant growth and development and eventually yield even if the lack of water is transient. In potato, tuber yield is correlated with both harvest index (HI) and dry matter and therefore for breeding, it is critical to understand the 


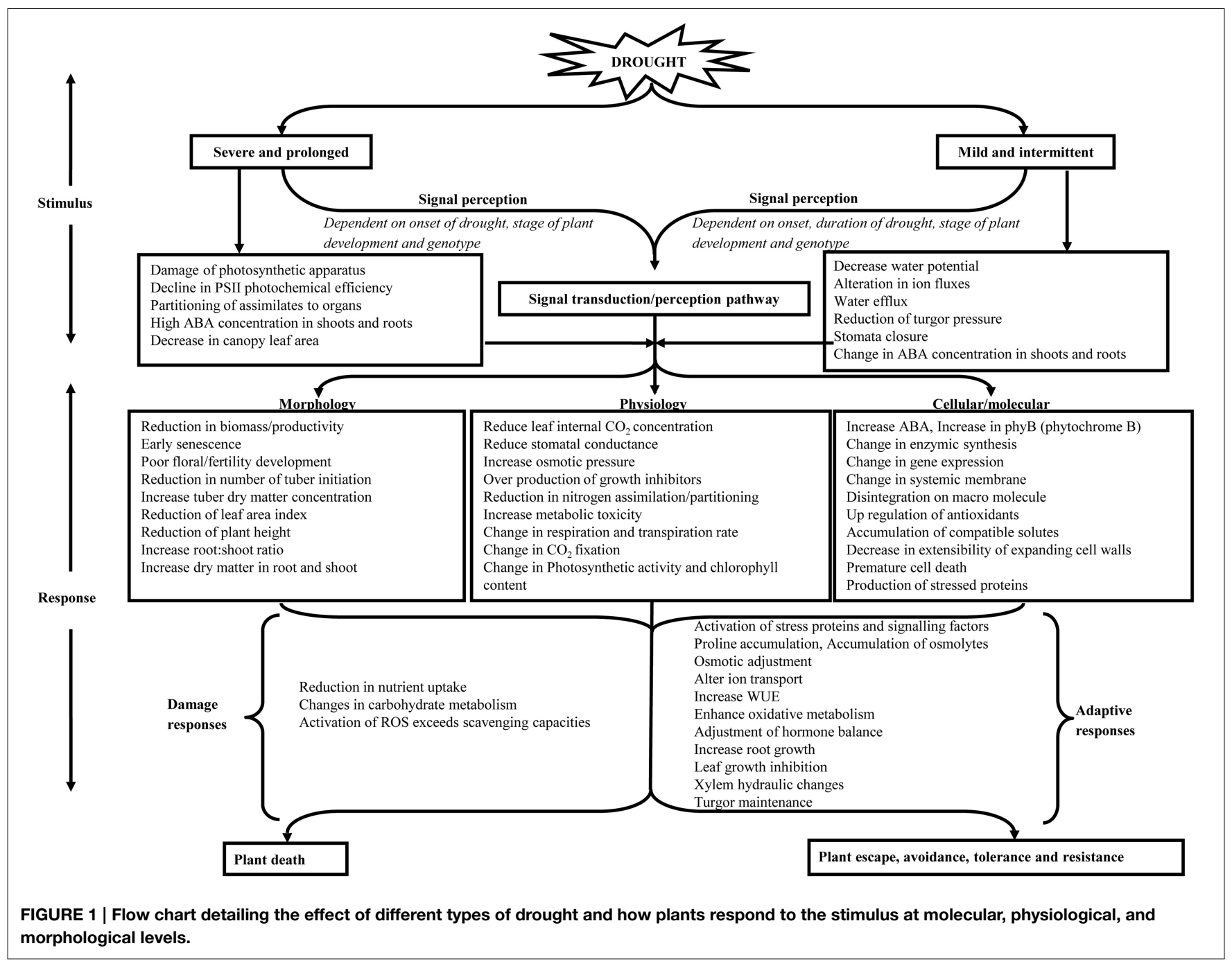

genotypic variation dependence on assimilate distribution and the dry matter production (Jefferies and Mackerron, 1987, 1993; Mackerron and Jefferies, 1988; Gregory and Simmonds, 1992; Jefferies, 1993a; Tourneux et al., 2003b). Little information is available on the effects of prolonged long term water shortage regimes but studies have widely examined short term lack of water consequences suggesting that soil moisture should not drop below $50 \%$ of crop available water in the soil for maximum yield (Mackerron and Jefferies, 1986). Drought in potato not only reduces yield, in that the crop may extract less of the available water from the soil in comparison with other crops (Weisz et al., 1994), but it can also harm product quality, for example by increasing common scab incidence (Mane et al., 2008).

At the molecular and biochemical level, plants perceive and respond to drought stress by dynamically shifting regulatory responses during transcription and protein expression, thus affecting many biochemical pathways and consequently physiological and developmental processes (Mane et al., 2008; Vasquez-Robinet et al., 2008). The reduction in photosynthesis as a result of drought is mediated through the stomatal and non-stomatal effects, where later involves decreased electron flow as a result of both photo-inhibitory damage and regulatory control of energy dissipation in the chloroplasts (Angelopoulos et al., 1996; Baker, 2008). Stomatal closure decreases $\mathrm{CO}_{2}$ availability in the mesophyll, and changes in the electron transport and biochemical pathways (Boyer, 1976) all contributing to reduced photosynthesis (Cornic et al., 1983; Genty et al., 1987) under water deficit stress. Biochemical changes include decreased ribulose bisphosphate (RuBP) synthesis (Gimenez et al., 1992), decreased Rubisco activity and decreased carboxylation efficiency (Martin and Ruiztorres, 1992) or both (Faver et al., 1996). The progressive decrease in maximum metabolic capacity under stress saturates photosynthetic rate and thus suggests, implicates photosynthetic carbon reduction cycle enzymes, including RuBP carboxylase/oxygenase (Rubisco). Limitation of RuBP synthesis is probably caused by inhibition of ATP synthesis, due to progressive inactivation or loss of coupling factor resulting from increasing ionic $\left(\mathrm{Mg}^{2+}\right)$ (Lawlor, 2002). Selective enhancement of Rubisco activase capacity could partly enhance photosynthesis under stress, but this enhancement would generally be small (Parry et al., 2013). At the electron transport level, decreased $\mathrm{CO}_{2}$ assimilation leads to reduced 


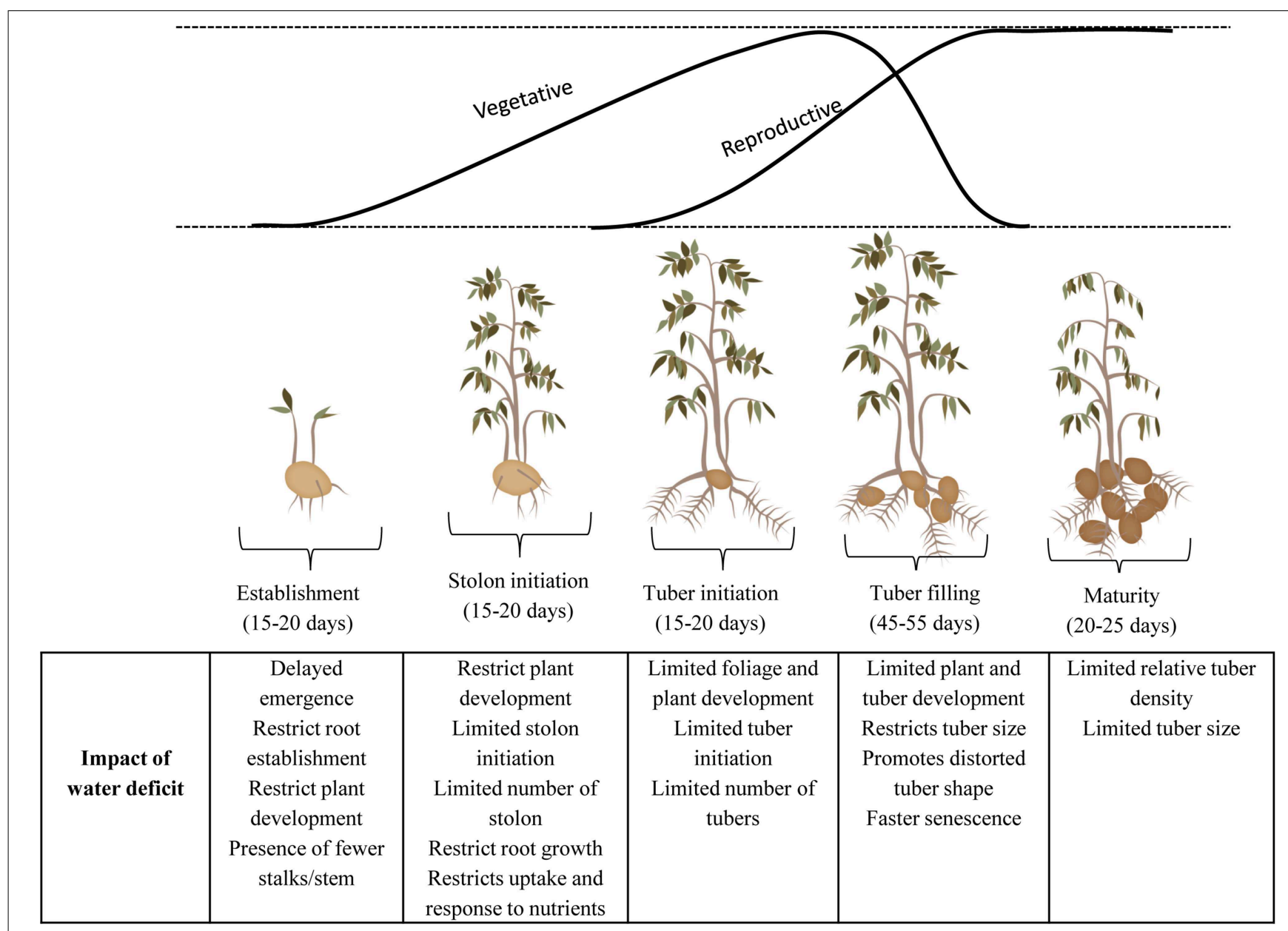

FIGURE 2 | Effect of water stress at different growth stages of potato.

regeneration of NADP+ in the Calvin cycle (Schapendonk et al., 1989; Cruz de Carvalho, 2008) resulting in concomitant generation of reactive oxygen species (ROS) and potential photo-inhibitory damage. Moreover, decreased intercellular $\mathrm{CO}_{2}$ concentration (as stomata close) favors oxygenation of RuBisCO which can also contribute to ROS production (Cruz de Carvalho, 2008). Figure 1 provides a detailed description of plant response to drought, stimulus to different types of drought, their effect on signaling pathways and plant adaptive responses. Different signaling pathways initiate phosphorylation cascades and activate appropriate transcription factors which trigger cellular responses under drought. These transcription factors regulate gene expression as a primary response of the plant resulting in plant stress adaptation (Rensink et al., 2005). Cytosolic $\mathrm{Ca}^{2+}$ is implicated as a cellular sensor second messenger in signal transduction, intracellular communication, and coordination of parts of recipient cells toward a behavioral objective (Sanders et al., 2002; Trewavas, 2002). In addition to localized responses there is compelling evidence for an important role for long-distance signaling, for example, abscisic acid (ABA) as a major chemical root to shoot stress signal in plants grown under dry conditions (Davies and Zhang, 1991; Davies et al.,
2002; Dodd, 2005; Hey et al., 2010). As a response to drought signal, the dosage of plant hormone ABA rises relative to stress severity and it represents a key signal in cellular response by activating the expression of different drought responsive genes (Chaves et al., 2003). Other hormonal signals sent to the shoot through transpiration stream along with ABA upon drought perception include ethylene and Gibberellic acid (GA). Studies have revealed that these hormones invoke responses in both mature and young leaves, with ABA response in mature leaf cells and ethylene and GA response in dividing and expanding leaf cells (Skirycz et al., 2010; Verelst et al., 2010). Similarly, Jasmonic acid (JA) or Jasmonates are shown to be important cellular regulators activating signal transduction pathway between stress perception and response under drought conditions (Wasternack and Parthier, 1997; Du et al., 2013; Lee et al., 2013). Some protein families serve as an interface of ABA, JA, and (GA) signaling, suggesting a pivotal functional involvement of lipidderived signaling in abiotic stress responses (Golldack et al., 2014). Compatible solutes including amino acids, ammonium compounds, sulfonium compounds, sugars, and polyols protect cellular structures (Chen et al., 2007). To protect plant enzymes and proteins from denaturizing upon drought stress, compatible 
solutes help to stabilize enzymes (Büssis and Heineke, 1998). The differential distribution and accumulation response of plants to this complex interaction defines their status toward survival or death. Plant cell death under severe drought stress occurs when concentration in ROS exceeds the scavenger potential with a consequence of irreparable damage to different plant cells including lipids, proteins, and deoxyribonucleic acid (DNA).

\section{Adaptive Response}

Plants respond to limiting water availability through a complex series of adaptive changes often accompanied by deleterious pleiotropic effects (Chaves et al., 2002; Jones, 2014). In an agricultural context farmers and breeders tend to define drought tolerant cultivars as those that maintain yield under drought conditions. Water deficit elicits responses that are expressed on growth, reproduction, partitioning of assimilates, survival, and death. These adaptive responses can be short term physiological regulation, cellular reversible adjustments, structural irreversible adjustments, and genotypic adjustments. The evolutionary responses to water stress are seen in light of genetic adaptation which produces specialized set of traits that allows them to prevail (Körner, 2003). Adaptation of plants to drought can involve avoidance or tolerance and thus stress adjustment scenarios that can be partitioned into (i) avoidance of tissue water deficits/dehydration, (ii) tolerance of tissue water deficits, and (iii) efficiency mechanisms (Turner, 1986; Jones, 2014). Avoidance of tissue water deficits (drought resistance according to Levitt, 1980) can be achieved by means of "drought escape," where a plant grows only during periods of ample water availability and often involves rapid phenological development. The drought escape process is significant in arid regions where adapted annuals might combine short life spans with high rates of growth and gas exchange while utilizing the maximum moisture content in soil (Maroco et al., 2000). Avoiding tissue dehydration can also be achieved by enhanced water uptake associated with adaptive aspects such as increased root depth, altered rooting patterns (Jackson et al., 2000) or by reduced water loss as a result of mechanisms involving stomatal closure or adjustments to the leaf energy balance through reductions in light absorption or modifications to heat and mass transfer in the leaf boundary layer (Larcher, 2000; Mitra, 2001; Jones, 2014). High stomatal resistance can be observed when potato leaf temperature is above $25^{\circ} \mathrm{C}$ while vapor pressure gradient is relatively constant $(\mathrm{Ku}$ et al., 1977) resulting to significant reduction in transpiration. The closure of potato stomata under high leaf temperature is a reflection of adaptation to a cooler environment ( $\mathrm{Ku}$ et al., 1977). Notably, the increased stomatal resistance may not result to proportional decrease in transpiration rate because for a given reduction in transpiration due to stomatal closure, the increase in leaf temperature would depend strongly on environmental factors, particularly the radiation load on the leaf, and the heat transfer coefficient of the air (Hsiao, 1973). Non-stomatal factors in the leaf, often referred to as "mesophyll," cause significant reductions in transpiration as water stress develops. In addition, water deficit affects stomata via its effect on ABA levels or on plant hormonal balance (Chaves, 1991).
Although stomatal density and stomatal size play an important role in determining the transpiration rate and leaf conductance and especially providing a rapid response to water deficits, much of the most important control of water loss over the life cycle of a crop is achieved by adjustments to leaf area (Wolfe et al., 1983; Jones, 2014). Tolerance of tissue water deficits most commonly involves maintenance of turgor, even when the tissue water potential declines, either through osmotic adjustment (OA) (Morgan, 1984) or as a result of the presence of rigid cell walls or decreased cell size (Wilson et al., 1980). The substantial differences between species in their ability to tolerate tissue water deficits and thus continue metabolism at low water potentials is often associated with the build-up of socalled "compatible" solutes. Our functional definition of drought tolerance is based on combination yield stability and high relative yield under water deficits. This has been proposed as useful selection criterion for adaptation under varying degree of water deficit (Pinter et al., 1990). Potential efficiency mechanisms for improvement of crop drought tolerance include improvements in the water use efficiency (WUE) and improvements in the efficiency with which assimilate is converted to harvestable yield (HI). In practice a plant may combine a range of drought tolerance mechanisms (Ludlow, 1989), but it is important to note that there is an important trade-off involved with many "drought tolerance" mechanisms as they may reduce potential yield: for example stomatal closure conserves water but also reduces photosynthetic assimilation.

Understanding the interactions between the various biochemical, molecular and physiological mechanisms for stress adaptation is vital for identifying traits that might improve stress tolerance in crops through both conventional breeding and transgenic strategies (Evers et al., 2010). In the context of climate change, there is also an urgent need to understand and develop potato management practices that will help adaptation to water deficit and their interaction with traits that confer tolerance or resistance to stress. This review discusses the current state of knowledge in trait identification with evidence of our understanding of drought tolerance in potato and further highlights the strategies and mechanisms being used to address adaptation. The review also discusses the use of new "phenotechnological" platforms and how they can be used to narrow the gap between genotyping and phenotyping for drought stress and to enhance breeding practices.

\section{Drought Effects on Potato}

\section{Physiological and Morphological Responses}

Physiological responses are variety dependant and vary with source of the seed or physiological age of the tubers (Steckel and Gray, 1979). The differences in source may influence patterns of foliage growth and yield as well as the number of root primordia and the eventual size of root system (Wurr, 1978). As might be expected, physiological responses to drought are often more closely associated with "predawn" water potential than with daytime water potentials (Jones, 2007). Physiological response strategies include drought sensitive stomata which result in low transpiration rates and relatively increased intrinsic WUE 
regardless of radiation level and thus promote growth in areas with limited water availability (Coleman, 2008). Transpiration is affected by leaf area, root to leaf ratio, leaf orientation, leaf shape, leaf surface characteristics (pubescence), leaf thickness, and distribution of stomata. An overview of the studies highlighting the impact of drought on morphological/physiological traits in potato is shown in Table $\mathbf{1}$ (with guidance from Figure 1) and the crop stages at which these characters are influenced are highlighted in Figure 2.

Plants under water stress show a decrease in leaf conductance $\left(g_{1}\right)$ which largely declines in parallel with leaf water potential $\left(\Psi_{1}\right)$ with efficient water conservative strategy dependant on the characteristics of canopy architecture such as canopy area, open/close canopy, leaf orientation, and cuticular transpiration rates. Potatoes exhibit isohydric characteristic with soil water potential $\left(\Psi_{\text {soil }}\right)$ and stomatal conductance $\left(g_{s}\right)$ decreasing under water stress while maintaining $\Psi_{1}$ similar to values obtained from non stressed conditions (Liu et al., 2005) suggesting delay in onset of stress. Predawn $\Psi_{1}$ and $g_{s}$ can therefore be used as parameters for water stress as they exhibit coherent relationship with growth and yield In potato, water stress studies have shown reduction in expansion of stems and leaves, leading to reduced foliage, reduced canopy, reduced leaf area index, decreased shoot biomass, and finally reduction in dry matter content (Jefferies, 1992, 1993b; Jefferies and Mackerron, 1993; Dallacosta et al., 1997; Deblonde et al., 1999; Deblonde and Ledent, 2001; Mane et al., 2008; Albiski et al., 2012; Anithakumari et al., 2012). These morphological responses depend on the time of stress (development stage) and also whether the stress is short or long term. Stress at stolon initiation and tuber initiation stages not only restrains foliage and plant development but also limits the number of stolons leading to reduced tuber numbers and therefore, reduced HI and dry matter with effects on final yield (Fasan and Haverkort, 1991; Deblonde and Ledent, 2001; Lahlou et al., 2003; Tourneux et al., 2003b; Evers et al., 2010). In some cases, studies have shown some contrasting effects on the morphological and physiological traits, which can be attributed to genotype $\mathrm{x}$ environment interaction. Contrasting reports of increased HI (Fleisher et al., 2013) and reduced HI (Fasan and Haverkort, 1991) can be credited to varying enviromental conditions used for the studies. A controlled sunlit soil-plantatmosphere research (SPAR) chamber with short term drought cycles was used in the former while the latter were grown under a permanent rain shelter in mobile containers. Root length has been reported to decrease under water stress using both in vitro screening (Albiski et al., 2012) and terminal drought evaluation (Auber et al., 2013). This contrasts with an earlier report (Jefferies, 1993a) that showed a constant root length while using self- and reciprocal grafts as planting materials with scions having a dominant effect in determining the partitioning of dry matter between shoot, root and tubers. Studies by Katerji and colleagues reported significant decrease in WUE when crops are grown in clay soil as during the active growing phase, a reduced water uptake occurs in the plants growing in the clay soil (Katerji and Mastrorilli, 2009) contradicting the results showing WUE not affected by soil type and salinity (Karam et al., 1996). Similar contradictory results have been reported for stolon numbers, with drought either reducing the stolon number (Haverkort et al.,
1990) for a series of experiments in plots, in pots or in containers in a glasshouse or under a rain shelter environment or increasing the number (Lahlou and Ledent, 2005) for other experiments under field and green house conditions. In all these contrasting studies, the environmental conditions, soil type, stress severity and phenological stage of stress induction differed and may have led to the variability in results.

Plant size, reduced leaf area, early maturity, and prolonged stomata closure are key traits in response to mitigating the effect of drought on plants (Weisz et al., 1994; Mahan et al., 1995; Karamanos and Papatheohari, 1999; Farooq et al., 2009; $\mathrm{Xu}$ et al., 2009). Similarly, the ability of potato to form a large "above ground" biomass has been shown to be an effective insurance against soil water deficit (Schittenhelm et al., 2006). As discussed above, plant response to drought may involve avoidance or tolerance. While avoidance and resistance responses involves morphological restraints, change in canopy size, area and anatomy and increase stomatal and cuticular resistance, tolerance is primarily attributed to maintenance cell turgor that includes $\mathrm{OA}$ and cellular or tissue elasticity. The limitation in measuring large number of genotypes for traits linked to tolerance without high throughput approaches has led to the use of transgenic approaches to bioengineer crop plants for tolerance (discussed in next Section).

Crop growth models allow us to evaluate the complexity of drought tolerance mechanisms and should help to provide a basis for identification of optimal strategies for any specific environmental combination. For example, the closing of stomata early in response to drought can save water for future growth at the expense of current growth but without affecting final growth and assimilate product (Spitters and Schapendonk, 1990). Although work is still being carried out to understand the physiological basis for this association, carbon isotope discrimination $\left(\delta^{13} \mathrm{C}\right)$ shows a significant positive correlation with plant height and the dry biomass of the plant foliage (Legay et al., 2011; Anithakumari et al., 2012). $\delta^{13} \mathrm{C}$ measures the ratio of stable carbon isotopes $\left({ }^{13} \mathrm{C} /{ }^{12} \mathrm{C}\right)$ in the plant dry matter compared to the ratio in the atmosphere (Condon et al., 1990). In a water deficit condition, $\delta^{13} \mathrm{C}$ represents a reliable estimator of stomatal conductance (Condon et al., 2002) and WUE in crops (Turner, 1997; Tambussi et al., 2007). Studies show that drought tolerant genotypes exhibited high WUE, stomatal control, and root elongation by maintaining photosynthesis and putative sucrose export to tubers under drought exposure. Studies show that high $\mathrm{CO}_{2}$ assimilation rate favors high $\mathrm{N}$ assimilation which in turn up-regulates nitrate reductase activity (NR), with lower decrease in NR associated with drought tolerance (Balasimha and Virk, 1978; Das et al., 2005).

\section{Drought Responsive Genes}

Stress responsive expression is thought to be an important mechanism of adaptation as it plays an important role in tolerance. Several studies have cataloged a large number of genes showing differential expression during stress treatment both in cereals and model crops. Although this list can be differentiated into WUE, avoidance and escape and finally tolerance based on traits associated, this paragraph compiles them under one heading as these mechanisms are interactive and 
TABLE 1 | Summary of drought impact on different morphological and physiological traits and summarized literature search highlighting these effects in potato.

\begin{tabular}{|c|c|c|}
\hline $\begin{array}{l}\text { Morphological/physiological } \\
\text { traits }\end{array}$ & Decreasing references & Improving references \\
\hline Productive foliage (stem and leaf) & $\begin{array}{l}\text { Jefferies and Mackerron, 1987, 1993; Fasan and Haverkort, 1991; Shock } \\
\text { et al., 1992; Dallacosta et al., 1997; Deblonde et al., 1999; Albiski et al., } \\
2012\end{array}$ & - \\
\hline Stem thickness & Albiski et al., 2012 & \\
\hline Plant dry matter & $\begin{array}{l}\text { Jefferies and Mackerron, 1987; Jefferies, 1992; Albiski et al., 2012; Fleisher } \\
\text { et al., } 2013\end{array}$ & Jefferies, 1993a; Jefferies and Mackerron, 1993 \\
\hline Canopy coverage & Jefferies and Mackerron, 1993 & - \\
\hline $\begin{array}{l}\text { Leaf dry mass, leaf area index } \\
(\mathrm{LAl}) \text {, leaf area duration (LAD }\end{array}$ & Fasan and Haverkort, 1991; Lahlou et al., 2003; Albiski et al., 2012 & - \\
\hline Leaf growth & Jefferies and Mackerron, 1993; Weisz et al., 1994 & - \\
\hline Leaf water potential & Moorby et al., 1975; Haverkort et al., 1991; Heuer and Nadler, 1998 & - \\
\hline Diffusive leaf resistance & - & lerna and Mauromicale, 2006 \\
\hline Leaf osmotic potential & Heuer and Nadler, 1998 & - \\
\hline Leaf sugar concentration & - & Moorby et al., 1975 \\
\hline Number of green leaves & Fasan and Haverkort, 1991; Deblonde and Ledent, 2001 & - \\
\hline Plant water content & Albiski et al., 2012 & - \\
\hline Plant Height & $\begin{array}{l}\text { Fasan and Haverkort, 1991; Shock et al., 1992; Deblonde and Ledent, } \\
\text { 2001; Albiski et al., } 2012\end{array}$ & - \\
\hline Tuber yield & $\begin{array}{l}\text { Jefferies and Mackerron, 1987, 1989; Miller and Martin, 1987; Lynch and } \\
\text { Tai, 1989; Spitters and Schapendonk, 1990; Fasan and Haverkort, 1991; } \\
\text { Jefferies, 1992; Martin et al., 1992; Shock et al., 1992, 1998; Karafyllidis } \\
\text { et al., 1996; Dallacosta et al., 1997; Steyn et al., 1998; Deblonde and } \\
\text { Ledent, 2001; Lahlou et al., 2003; Tourneux et al., 2003b; Proietti et al., } \\
\text { 2005; lerna and Mauromicale, 2006; Shiri-E-Janagard et al., 2009; Evers } \\
\text { et al., 2010; lerna et al., 2011; Alva et al., } 2012\end{array}$ & - \\
\hline Tuber dry matter & Levy, 1983; Jefferies and Mackerron, 1989, 1993; Deblonde et al., 1999 & $\begin{array}{l}\text { Steckel and Gray, 1979; Jefferies and Mackerron, } \\
\text { 1987, 1993; Jefferies, 1992; Nadler and Heuer, } 1995\end{array}$ \\
\hline Number of tuber & $\begin{array}{l}\text { Mackerron and Jefferies, 1986; Lynch and Tai, 1989; Martin et al., 1992; } \\
\text { Shock et al., 1992; Deblonde and Ledent, 2001; Lahlou et al., 2003; } \\
\text { Onder et al., } 2005\end{array}$ & - \\
\hline Tuber specific gravity & Shock et al., 1993, 2003; Eldredge et al., 1996 & \\
\hline Stem-end reducing sugar & - & $\begin{array}{l}\text { Levy, 1983; Shock et al., 1993; Nadler and Heuer, } \\
\text { 1995; Eldredge et al., } 1996\end{array}$ \\
\hline Harvest index & Fasan and Haverkort, 1991 & Fleisher et al., 2013 \\
\hline Stolon number & Haverkort et al., 1990 & Lahlou and Ledent, 2005 \\
\hline Tuber quality at storage & - & Shock et al., 1992 \\
\hline Total soluble solids & Levy, 1985 & Shock et al., 1993 \\
\hline Tuber osmotic potential & Levy, 1985 & - \\
\hline $\begin{array}{l}\text { Partitioning of assimilate into } \\
\text { tubers }\end{array}$ & - & Jefferies and Mackerron, 1989 \\
\hline Root length & Albiski et al., 2012; Auber et al., 2013 & Jefferies, 1993a \\
\hline Root number and thickness & Albiski et al., 2012 & - \\
\hline Root biomass & Mane et al., 2008 & - \\
\hline Root water potential & Liu et al., 2005 & - \\
\hline Root dry matter & - & Jefferies, 1993a; Lahlou and Ledent, 2005 \\
\hline Root: shoot ratio & - & Jefferies, 1993a \\
\hline
\end{tabular}

response of one pathway affects the other. Studies have shown that glycolysis gene transcription and amino-acid degradation are more strongly repressed in drought tolerant cultivars when compared to drought susceptible ones (Evers et al., 2010). Drought stress led to strong repression of photosynthesis-related genes in drought tolerant cultivar (Reiter and Vanzin, 2001;
Evers et al., 2010). Under stress recovery, genes associated with PSII showed that genotype specific activation responses increased sucrose accumulation and cell wall biosynthesis (Mane et al., 2008). There is evidence of high mitochondrial metabolic activity in a drought resistant cultivar (Vasquez-Robinet et al., 2008) while a susceptible cultivar was characterized with higher 
levels of proline, trehalose, and GABA ( $\gamma$-aminobutyric acid) (Vasquez-Robinet et al., 2008). Several genes associated with mitochondrial function were more negatively affected in drought susceptible genotypes. Dihydrolipoamide dehydrogenase and ADP-sugar biphosphatase were activated in drought resistant clones but repressed in drought susceptible clones. Chloroplastlocalized antioxidant and chaperone genes were more highly expressed in drought resistant cultivars whereas ABA-responsive transcriptional factors (TFs) were more highly expressed in drought susceptible ones (Vasquez-Robinet et al., 2008). Evaluation under in vitro control and water-stressed conditions identified putative candidate genes for drought tolerance as transcription factors and signaling molecules, such as protein kinases and ERF1 (Ethylene Response factor 1) (Anithakumari et al., 2011, 2012). Silencing of a CBP80 (nuclear cap-binding protein) gene in the cultivar Desiree increases water deficit tolerance through initiating Cap-Binding Complex (CBC) that recognizes and binds to the cap structure of RNA polymerase II transcripts in the nucleus (Papp et al., 2004; Kierzkowski et al., 2009; Pieczynski et al., 2013). The drought tolerant plant silenced for the CBP80 gene exhibited an ABA-hypersensitive stomatal closing response (Pieczynski et al., 2013). Products of miR159, MYB33, and/or MYB101 genes that act downstream of $C B P 80$ have been shown to be involved in the ABA- mediated regulation of potato responses to drought and similar studies have also identified and characterized microRNA families for drought stress response and their putative target genes including miR171 (stu-miRNA171a, b, and c), miR159, miR164, miR166, miR390, miR395, miR397, miR398, miR408, and miR482 (Hwang et al., 2011a,b; Pieczynski et al., 2013; Zhang et al., 2013). Most of the genes identified in the above studies showing differential down regulation were involved in photosynthesis and carbohydrate metabolism, including chlorophyll a-b binding proteins, fructose-1, 6-bisphosphatase trehalose-6-phosphate synthase while sucrose synthase was up-regulated (Hwang et al., 2011a,b; Kondrak et al., 2012).

Changes in transcript profiling upon imposition of polyethylene glycol (PEG) induced water stress show that up-regulated genes were prevalently involved in carbohydrate metabolism, cellular communication, and signal transduction whereas down regulated genes mostly include ATP-dependent RNA helicase and cytochrome P450 followed by vacuolar ATP synthase and genes involved in protein synthesis (Leone et al., 1994; Ambrosone et al., 2011; Zhang et al., 2014). Genes involved in different pathways of protein metabolism participate in the early response, controlling protein folding, and protein turn-over/degradation thus contributing to regulation of protein synthesis while preventing major cellular damage under water deficit (Ambrosone et al., 2013). Table 2 shows the list of differential gene expression using validated RT-PCR and microarray using leaf material under water and PEG induced stress in potato. Dehydrins (group 2 members of late embryogenesis abundant protein family) are shown to be associated with crucial protective functions through membrane stabilization, resistance to osmotic pressure and protection of proteins-the so-called chaperone function (Allagulova et al., 2003; Lopez et al., 2003; Agoston et al., 2011). Studies show that the dehydrins interact with membranes in the interior of cells and reduce dehydration induced damage through their ability to replace water and, through their hydroxyl groups (Baker et al., 1995) and dehydrins are shown to play a fundamental role in plant response and adaptation to abiotic stress (Hanin et al., 2011). Comparing expression analysis in non-transgenic potato and AtDREB1A (Dehydrin responsive element binding protein) transgenic potato suggest that potato may have mechanisms in abiotic stress tolerance controlled by native TFs similar to AtDREB1A (Watanabe et al., 2011). The over expression of StMYB1R-1 (MYB-like transcription factor) improved plant tolerance to stress and it is thought that the induced upregulated expression of AtHB-7 (Arabidopsis homeobox gene), RD28 (Responsive to desiccation), ALDH (Aldehyde dehydrogenase), and ERD15 (Early response to dehydration) under drought stress conditions enhances tolerance (Shin et al., 2011). Induction of protein phosphatase $2 \mathrm{C}$ gene was positively associated with yield maintenance under drought with drought tolerant cultivars expressing higher levels of DREB transcription factor (Schafleitner et al., 2007b,c).

Constitutive overexpression of the ScCBFI gene from Solanum commersonii in transgenic Solanum tuberosum and $S$. commersonii plantlets grown in vitro showed better overall plant growth and root development under drought stress, providing evidence for a drought adaptation response (Teresa Pino et al., 2013). Transgenic potato plants that overexpress the Arabidopsis thaliana DHAR gene (AtDHAR1) in the cytosol show greater shoot extension than the WT plants due to elevated AsA (Ascorbate) leading to enhanced tolerance to drought and salt stress (Eltayeb et al., 2011). TPS1-expressing (Trehalose 6 phosphate synthase gene) transgenic potato lines effectively retain water under drought treatment and maintained an acceptable level of photosynthetic processes for a longer time than wild type as the transgenic lines had lower $\mathrm{CO}_{2}$ fixation rate and stomatal densities under optimal growth conditions than the non-transformed control plants (Stiller et al., 2008). The studies discussed above show that gene expression response under stressful conditions strongly depends upon the genotypic variation.

\section{Stress Combinations}

Plants interact with both abiotic (temperature, drought, and salinity) and biotic (herbivores and pathogens) factors either individually or in combination. Combination of stresses alter metabolism in ways that may differ from responses to different stresses applied individually (also dependent on species), as molecular signaling pathways controlling abiotic and biotic stresses may interact or counteract one another (Rizhsky et al., 2004; Mittler, 2006). As for abiotic stresses, changes in temperature, nutrient and the presence of heavy metals, toxins, and oxidants have the potential to contribute to plant stress and some of the aforementioned stress combinations can cause cell injury and produce secondary stresses such as osmotic and oxidative ones (Wang et al., 2003) with negative effects on yield, tuber quality, and market value (Wang-Pruski and Schofield, 2012; Rykaczewska, 2013). In Arabidopsis, transcriptome and metabolic profiling of plants subjected to a combination of 
TABLE 2 | List of validated (RT-PCR and microarray) up-regulated (+) and down-regulated (-) genes implicated in drought stress response in potato.

\begin{tabular}{|c|c|c|c|c|}
\hline $\begin{array}{l}\text { Stress } \\
\text { condition }\end{array}$ & Source & Gene family (gene) & Regulation & References \\
\hline PEG & Cell & $\begin{array}{l}\text { AP-1 complex ( } \gamma \text {-adaptin), catalase isozyme } 1 \text { (AW906659), sucrose synthase } 2 \\
\text { (BE471969), LRR- receptor kinase (BF188424), hydroxyproline-rich extension } \\
\text { (BF188513), protein heparanase (BF188529), 14-3-3 protein family (BE471953) }\end{array}$ & + & Ambrosone et al., 2011 \\
\hline Water & Leaf & Sucrose synthase genes & + & Evers et al., 2010 \\
\hline PEG & Leaf & GTP-binding proteins (BE341142) & + & Ambrosone et al., 2011 \\
\hline PEG & Cell & Sphingolipid protein membrane (Serinc) & - & Ambrosone et al., 2013 \\
\hline PEG & Cell & $\begin{array}{l}\text { Phe ammonia-lyase (PAL1), Peroxidase (Peroxidase 17), sphingolipid protein membrane } \\
\text { (Sphingolipid Desaturase), ubiquitin-conjugating } \\
\text { Enzyme (ubiquitin-conjugating enzyme E2), ribosomal RNA components (ribomosal } \\
\text { L41,18s rRNA), heat shock proteins (HSP 20.2, HSP 83), }\end{array}$ & + & Ambrosone et al., 2013 \\
\hline Water & Leaf & Elongation factor $(E F 1 \alpha)$ & + & Kondrak et al., 2011 \\
\hline Water & Leaf & Ubiquitin-proteasome protein (UBC2) & + & Kondrak et al., 2011 \\
\hline Water & Leaf & $\begin{array}{l}\text { Thaumatin protein (PGSC0003DMG400003569), low-temperature-induced } 65 \mathrm{kDa} \\
\text { protein (PGSC0003DMG400014293), jasmonate ZIM-domain protein } \\
\text { 1(PGSC0003DMG400002930), ethylene-responsive late embryogenesis } \\
\text { (PGSC0003DMG400000066), ascorbate peroxidase (PGSC0003DMG401001731), } \\
\text { WRKY transcription factor } 4 \text { (PGSC0003DMG400009051), non-specific lipid-transfer } \\
\text { protein (PGSC0003DMG400032250), auxin repressed/dormancy associated protein } \\
\text { (PGSC0003DMG400012826), early-responsive to dehydration } 7 \\
\text { (PGSC0003DMG402006194), gibberellin 2-oxidase (PGSC0003DMG400009021), } \\
\text { ethylene-responsive transcription factor (PGSC0003DMG400014240), ERF114 MYB } \\
\text { transcription factor (PGSC0003DMG400022399), hydroxyproline-rich glycoprotein } \\
\text { GAS31(PGSC0003DMG400031105), }\end{array}$ & + & Zhang et al., 2014 \\
\hline Water & Leaf & $\begin{array}{l}\text { Germin (PGSC0003DMG400014027), abscisic acid receptor } \\
\text { PYL4(PGSC0003DMG400011033), polygalacturonase-1 non-catalytic subunit beta } \\
\text { (PGSC0003DMG400027019), transcription factor bHLH49 (PGSC0003DMG400019659) }\end{array}$ & - & Zhang et al., 2014 \\
\hline Water & Unspecified & $\begin{array}{l}\text { MYB-like transcription factor (StMYB1R-1), protein } 2 \text { (RD28), aldehyde dehydrogenase } \\
(A L D H 22 A 1) \text {, early responsive to dehydration (ERD15-like), homeodomain-leucine zipper } \\
\text { (HD-Zip) proteins (AtHB-7) }\end{array}$ & + & Shin et al., 2011 \\
\hline Water & Leaf & delta 1-pyrroline-5-carboxylate synthase (AtP5CS), & + & $\begin{array}{l}\text { Schafleitner et al., } 2007 a \text {; } \\
\text { Evers et al., } 2010\end{array}$ \\
\hline Water & Leaf & Proline dehydrogenase $(P D H)$ & $+/-$ & Schafleitner et al., 2007a \\
\hline Water & Leaf & $\begin{array}{l}\text { Galactinol synthase, arginine decarboxylase, spermidine synthase, proton gradient } \\
\text { regulation } 5\end{array}$ & + & Evers et al., 2010 \\
\hline Water & Leaf & Spermine synthase, raffinose synthase & $+/-$ & Evers et al., 2010 \\
\hline Water & Leaf & Chaperone Dna K, thioredoxin & $+/-$ & Vasquez-Robinet et al., 2008 \\
\hline Water & Leaf & Ppiase Chl, Heat shock protein (ER HSP 110 and ER HSP 90) & + & Vasquez-Robinet et al., 2008 \\
\hline Water & Leaf & Glutathione-S-transferase, glutathione synthetase, Chaperone DnaJ & - & Vasquez-Robinet et al., 2008 \\
\hline Water & Leaf & $\begin{array}{l}\text { chlorophyll a-b binding proteins, fructose-1,6-bisphosphatase, trehalose-6-phosphate } \\
\text { synthase }\end{array}$ & - & Kondrak et al., 2012 \\
\hline Water & Leaf & MADS-box proteins (AGL8 and AGL24), GATA factor, Alfin 1 TF & - & Kondrak et al., 2011 \\
\hline Water & Leaf & SU11B, Rubisco small subunit (RBCS-3B) & + & Kondrak et al., 2011 \\
\hline
\end{tabular}

PEG, Polyethylene glycol; +, up regulation;-, down regulation; +/-, up and down regulation.

drought and heat stress showed a partial combination of two multi-gene defense pathways and an accumulation of sucrose and other sugars such as maltose and glucose (Rizhsky et al., 2004). Evidence of evolutionary conservation of stress responses to salt, osmotic, heat, and ABA stimuli has been highlighted by Massa et al. (2013). Net photosynthesis and respiratory potential were lower in drought exposed plants 4 weeks after treatments [well watered and drought and with and without selenium (Se) foliar spraying] with Se inducing high respiratory potential in the leaves (Germ et al., 2007). Higher efficiency of energy conversion in PSII, expressed by higher quantum yield was observed in
Se treated plants 2 weeks after treatment (Germ et al., 2007). Water deficit coupled with silicon ( $\mathrm{Si}$ ) application decreased total sugars and soluble protein concentration in potato leaves, with $\mathrm{Si}$ concentrations increasing in potato leaves under deficit conditions (Crusciol et al., 2009). Exposure of $\mathrm{SO}_{2}$ under well watered conditions produced defoliation and dry weight reduction of leaf, stem, and tubers while there was usually no dry weight reduction induced by $\mathrm{SO}_{2}$ under water stressed condition (Qifu and Murray, 1991). Well watered plants accumulated significantly higher leaf sulfur than did water-stressed plants at the same concentration of $\mathrm{SO}_{2}$ (Qifu and Murray, 1991). The 
combined effect of nematode infection and water stress resulted in decreased potato tuber production with reduced uptake of total P, K, and Mg (Fatemy and Evans, 1986; Fasan and Haverkort, 1991; Haverkort et al., 1991). As the interaction between stresses sometimes are regulated by the same signaling and regulatory networks, therefore, understanding these regulators connecting different response pathways provide better opportunities to breed for stress tolerant crop/genotypes covering broad spectrum.

\section{Potential Traits for Drought Tolerance Breeding in Potato}

An ability to maintain economic yield under water deficits is a valuable trait whenever water availability is a problem. This can be achieved by improvements in dehydration avoidance, dehydration tolerance and in other traits linked to optimum growth and metabolism under stress (Okogbenin et al., 2013). Desirable drought phenotypic traits must be genetically associated with yield under stress, highly heritable, genetically variable, easy to measure, stable within the measurement period, and must not be associated with a yield penalty under unstressed conditions (Okogbenin et al., 2013). Potato yields depend on the timing of water stress within the growing period (Spitters and Schapendonk, 1990) and upon climatic and soil conditions (Tourneux et al., 2003a) and thus it is necessary to consider these factors before making recommendations of optimal phenotypes for any specific environments. One might expect some characters such as enhanced WUE or improved tolerance of given water deficits to be generally adaptive. This is not generally the case as there will usually be some corresponding cost (e.g., higher WUE usually comes at the expense of lower photosynthetic rates while tolerance of water deficits often has a metabolic cost). Indeed the important character is not WUE but the "effective use of available water" (i.e., tailored to the specific growing environment) (Blum, 2009). For this reason results from artificial (e.g., hydroponic or controlled environment) studies may not often have direct relevance to drought tolerance in the field, though they may help to identify genotypes with characters predicted to be of value in specific environments (e.g., low stomatal conductance for consistently water-limited environments). We discuss below a number of traits which have been suggested as being crucial contributors to the genetic improvement of drought tolerance. While highlighting these traits, we also want to highlight that success rate of recovery after re-watering also depends upon the pre-drought intensity, duration, and species (Xu et al., 2010). In addition the species specific variation in hydraulic potentials is critical in steering the dynamic response of plants during recovery (Blackman et al., 2009).

\section{Stomatal Characters}

Plants adapt to drought conditions either by decreasing water loss or by maintaining water uptake. OA results in an increase in solutes (organic solutes and inorganic ions) in plant cells leading to a lowered osmotic potential, which in turn can improve cell hydration, help maintain cell turgor in leaf tissue, maintain metabolic processes and thus enhance plant growth and yield under drought stress (Morgan, 1984; Ludlow and Muchow,
1990; Sanders and Arndt, 2012). Studies on the diploid mutant "droopy" in potato whose leaves wilt during day leading to premature leaf fall indicates the advantage of stomatal hydrostat in normal plants as wilting and tall and slim structure of "droopy" was not attributed to root or vascular system but stomatal opening. Interspecific differences occur in species in their response and relationship of stomatal conductance to leaf water potential as stomatal conductance is controlled by complex interaction of intrinsic and extrinsic factors and not soil water availability alone. Nevertheless, studies mainly show that stomata close with increasing drought. Therefore, measuring stomatal characters (size and frequency) and control of water loss can aid in identification of desirable genotypes. Stomatal size and frequency are factors which influence stomatal resistance since most of the water escape through the stomata (Wang and Clarke, 1993). Remote sensing techniques using the thermal range of the spectrum can be used as an indication for plant water status and early studies showed the relationship between canopy temperature measured (indirectly influenced by stomatal closure) and plant water status in potato (Dallacosta et al., 1997; Leinonen et al., 2006). Thus differences in canopy temperature can be used as a selection method for screening drought tolerance among potato genotypes (Prashar et al., 2013; Prashar and Jones, 2014). These screening methods can be used to phenotype large populations to identify chromosomal regions controlling stomatal opening and closing and toward breeding crops with optimal stomatal response with some plasticity in behavior, so that stomata remain open under ample water conditions but close as water deficits increase.

\section{Photosynthesis}

One of the primary physiological impacts of crop water scarcity is reduction of photosynthetic rate per unit leaf area (Moorby et al., 1975; Vos and Oyarzun, 1987; Schapendonk et al., 1989; Dallacosta et al., 1997; Deblonde and Ledent, 2001; Germ et al., 2007). The decreased net photosynthesis as a consequence of stomatal closure (Vos and Oyarzun, 1987; Trebejo and Midmore, 1990; Haverkort et al., 1991; Jefferies, 1994; Liu et al., 2005) and leaf area reduction under water stress are key contributors to yield loss under drought (Legay et al., 2011). Photosynthetically active radiation in plants is absorbed by chlorophyll and accessory pigments of chlorophyll-protein complexes which migrate to the reactive centers of PS I and II, where conversion of the quantum photosynthetic process takes place (Horton et al., 1996). Chlorophyll fluorescence helps in unraveling the different functional levels of photosynthesis including processes at the pigment level, primary light reactions, thylakoid electron transport reactions, dark enzymatic stroma reactions, and slow regulatory processes (Smillie and Nott, 1982; Maxwell and Johnson, 2000; O'Neill et al., 2006). The analysis of chlorophyll content and chlorophyll fluorescence parameters including initial fluorescence $\left(F_{0}\right)$, maximal fluorescence $\left(F_{\mathrm{m}}\right)$, variable fluorescence $\left(F_{\mathrm{v}}\right)$, and maximal quantum efficiency of PSII $\left(F_{\mathrm{v}} / F_{\mathrm{m}}\right)$ is considered an important approach for the evaluation of health or integrity of the internal apparatus during photosynthetic processes within a leaf while providing a platform for rapid and precise detection and quantification of plants 
tolerance to drought stress (Vertucci et al., 1985; Chaerle and van der Straeten, 2000; Clavel et al., 2006; Buerling et al., 2013). These parameters might estimate influence of stress on growth and yield, since these traits are closely correlated with the rate of carbon exchange (Fracheboud et al., 2004; Czyczylo-Mysza et al., 2011). They can serve as reliable indicators to evaluate the energetic and metabolic imbalance of photosynthesis and yield performance across genotypes under limited water/stress scenarios (Araus et al., 1998). Components of the photosynthetic apparatus could be damaged in drought sensitive genotypes while drought tolerant genotypes can decrease or evade impairment resulting from drought stress (Smillie and Nott, 1982; O'Neill et al., 2006). Genetic differences in photosynthetic capacity exist at intraspecific and interspecific levels, so the use of the photosynthetic capacity as a physiological marker could be realistic where a positive relationship between the photosynthetic performance and the growth under stress conditions has been confirmed (Ashraf and Harris, 2013).

Chlorophyll fluorescence provides rapid indicators and a method for the study of changes in photosynthetic capacity of potato under water stress (Anithakumari et al., 2012) while the ratio between $F_{\mathrm{v}}$ and $F_{\mathrm{m}}$ and the differences in the canopy temperature can be used as a selection method for screening drought tolerance among potato genotypes (Ranalli et al., 1997; Prashar et al., 2013; Prashar and Jones, 2014). Chlorophyll fluorescence parameters $F_{0}, F_{\mathrm{m}}, F_{\mathrm{v}}$, and $F_{\mathrm{v}} / F_{\mathrm{m}}$ show genotypic variation under drought stress in potato with drought stress having a reducing affect (Anithakumari et al., 2012). This is as a result of photoinhibition (Baker and Horton, 1987), reversible photoprotective down regulation or irreversible inactivation of PSII (Baker and Bowyer, 1994; Long et al., 1994). Water stress severity increase leads to a decrease in the heritability of $F_{\mathrm{v}} / F_{\mathrm{m}}$ (Jefferies, 1992; Zrùst et al., 1994; Anithakumari et al., 2012). There is evidence of a highly significant correlation between fluorescence emission and tuber yield with genotypes varying in response (Ranalli et al., 1997). A small decrease in quantum yield as a result of drought is associated with drought tolerance and this has been observed in early maturing varieties (Van Der Mescht et al., 1999; Anithakumari et al., 2012). Chlorophyll fluorescence parameters has the potential of separating genotypes according to their tolerance to water deficit (Newell et al., 1994).

Differences in leaf angle distribution can in principle affect light interception and photosynthesis (Jones, 2014), for example a theoretical analysis has shown that an increase in canopy leaf angle from 30 to $60^{\circ}$ should result in a potential increase in rate of dry matter accumulation of between 15 and $30 \%$ after complete leaf-area expansion in maize (Tollenaar and Bruulsema, 1988). A similar morphological shift could be considered for potato by breeding for more erect leaved canopies. It could be hypothesized that genotypes which maintain canopy expansion and maximum light interception will yield higher dry matter content and significant yield under limiting water (Frusciante et al., 1999). Although higher photosynthesis rates, and associated characters such as stay green, are associated with higher yields (Cattivelli et al., 2008), it does not necessarily mean that selection for high assimilation will improve drought tolerance, as such lines may use water faster and suffer more from drought.

\section{Water Use Efficiency (WUE)}

The growth and yield model of Passioura (1996) describes crop yield as the product of water uptake (WU), water-use efficiency (WUE), and HI. Improvement in any one of these components, while maintaining the others constant, can increase yield, but interactions can occur with increases in WU, for example, tending to be associated with lowered WUE. This means that selection for any one of these components must take account of effects on others. At the physiological level, WUE may be defined as the ratio of photosynthesis to transpiration as well as simultaneous ratio of net carbon assimilation to water transpiration of the stomata from the leaf (Xu and Hsiao, 2004; Guo et al., 2006). The leaf transpiration efficiency is determined by cellular solutes, specific ions, $\mathrm{pH}$, and $\mathrm{ABA}$ produced in the leaf or imported from the root (Blum, 2009). WUE at whole plant and crop level is relatively lower when compared to the leaf level because of water loss associated with non-photosynthetic process and respiratory carbon loss during conversion of initial photosynthate to biomass as well as fraction of total water inputs that is never taken up by the plant (Guo et al., 2006). The factors influencing plant transpiration and water use at the whole plant level under drought include growth duration (Mitchell et al., 1996), leaf permeability (Kerstiens, 2006), nocturnal transpiration (Caird et al., 2007), leaf desiccation (Blum and Arkin, 1984), leaf area and orientation (Xu et al., 2009), leaf growth (Weisz et al., 1994), and soil evaporation (Rebetzke and Richards, 1999). There is a tendency for WUE to increase as stomata close (Vos and Groenwold, 1989; Jones, 2014). The advantage of constitutive stomatal closure is expected to be only valid in consistently dry environments, where it can lead to enhanced WUE, but where drought occurrence is uncertain, constitutive closure is likely to be disadvantageous for yield unless genotypes show responsive flexibility in opening and closing dependent upon stress. In consistently dry environments, genotypes that can deplete soil moisture only slowly and may optimize crop WUE rather than maximizing short-term growth. Ideally they will continue until the soil water is depleted, at which point growth is halted (Elsharkawy et al., 1992). One might expect plants with higher stomata number per unit area, or with greater length and width, to lose more water, but there may be natural compensations between size and frequency (Jones, 1977), while stomatal movements can override such morphological differences (Jones, 1987). A low rate of cuticle transpiration may reduce leaf dehydration and promote leaf survival (Wang and Clarke, 1993). Early vigor has the potential of improving both WU and WUE, while deep roots and/or osmoregulation under appropriate conditions increase water extraction from the soil (Richards, 2006; Blum, 2011; Sadok and Sinclair, 2011).

Significant progress in assessing genetic variability in WUE was achieved after the establishment of the physiological links between $\delta^{13} \mathrm{C}$ and WUE (Farquhar and Richards, 1984; Farquhar et al., 1989). $\delta^{13} \mathrm{C}$ has been used as a surrogate for WUE and has been successfully used for tomato (Martin and Thorstenson, 1988), wheat (Rebetzke et al., 2002), and rice (Impa et al., 2005). Nevertheless, although understanding the inheritance of $\delta^{13} \mathrm{C}$ could be useful for the development of potato cultivars with high WUE (Anithakumari et al., 2012), an understanding of the 
relationship between TE, WUE and yield under different levels of water stress is important. Improvement of the WUE of a crop plant results in higher yield performance if high $\mathrm{HI}$ can be maintained as total biomass yield in drought environment is positively associated with WUE (Blum, 2009; Araus et al., 2012). TE is under genetic control (Masle et al., 2005) and excludes amount of water lost by soil evaporation, and hence should be considered as a potential trait for drought stress (Manavalan et al., 2009). It should be that WUE can primarily be the result of limited water use rather than a net improvement in plant production or assimilation and therefore for selection trait evaluation both for resource efficiency and final product is crucial. An effective breeding strategy will consider plant adaptive characteristics which drive effective use of water, resultant dehydration avoidance and yield potential (Blum, 2009).

\section{Maintenance of Water Status: Canopy Temperature and Development}

Plant water status maintenance is possible if the plant is equipped with the appropriate "hydraulic machinery" (Sperry et al., 2002) as well as additional traits to relieve the energy load on the plant as well as manage an effective use of water (Chaves et al., 2002; Blum, 2011). The state of water flux, transpiration, and the associated leaf water potentials can be used to comparatively phenotype toward identification of drought tolerant genotypes. The obvious limitation is the dynamic nature of the inherent traits modulating water status during the day. With a robust and automated phenotyping platform this problem can be circumvented by "dawn to dusk" measurements. Plants that can maintain adequate relative water content (RWC) for a longer period of time under drought exposure will have the greatest likelihood of continued metabolic functioning and survival and studies have been able to demonstrate that cultivars with greater drought resistance were able to maintain higher cellular hydration under drought conditions (McCann and Huang, 2008). The RWC has successfully been used in differentiating drought resistance and drought susceptible potato cultivars (Coleman, 1986). A relatively lower canopy temperature in drought stressed crop plants indicates maintenance of high stomatal conductance; this can indicate effective maintenance of tissue water status particularly by effective uptake of soil moisture or by other adaptive traits (Blum, 2009). Studies using various crops including wheat (Amani et al., 1996; Rebetzke et al., 2013), rice (Horie et al., 2006), sorghum (Mutava et al., 2011), and more recently potato (Prashar et al., 2013) have all reported that canopy temperatures can be associated with yield and could therefore be used as a selection technique (Jackson et al., 1981; Leinonen and Jones, 2004; Grant et al., 2007; Jones, 2007; Zia et al., 2013). Therefore, a better understanding of the mechanisms that regulate growth under water deficit, such as those involved in shutting down meristem activity will be vital in the development of new technologies to increase growth under stress (Tisne et al., 2010).

\section{Root Characters}

The morphology and architecture of the root system at any stage of development may influence the hydrostatic gradient. The resistance in the root system to water flow both radially (into the root) and axially (within the xylem) may be great enough to increase significantly the gradient, reduce the hydraulic conductivity and increase the canopy temperature (Mahan et al., 1995). Potato is very sensitive to water-stress when compared to other species (Porter et al., 1999) because of its shallow (Iwama and Yamaguchi, 2006) and sparse (Jefferies, 1993a) root system. The tendency for an increased root-shoot ratio under drought and for root growth to be maintained more than shoot growth (Jefferies, 1993a) are both likely to contribute to drought tolerance.

Breeding of new cultivars with excellent root quality that ensures absorption of water from deeper soil layers and under low soil moisture will help in more efficient utilization of water for potato production (Iwama, 2008). Differences in gross morphology, including the degree of branching and rooting depth may decrease the availability of water due to the inability of the root system to explore a larger soil volume and thus increase the gradient (Mahan et al., 1995). Genotypic differences have been reported for both rooting depth (Steckel and Gray, 1979; Tourneux et al., 2003a,b) and root growth volume (Mackerron and Peng, 1989; Jefferies, 1993a), while the positive correlation between root mass, shoot mass and final tuber yield have led to the suggestion of using root mass in the plow layer as a selection criterion (Iwama, 2008). One approach to the selection of deep rooting genotypes is to measure the pulling resistance (PR) of roots (Ekanayake and Midmore, 1992; Stalham and Allen, 2004). Differences in the ability of roots to continue to elongate under low water potential could also be an adaptation to water deficit (Westgate and Boyer, 1985; Spollen et al., 1993) as would more efficient rooting architectures (Porter and Semenov, 2005; Tardieu, 2012; Wishart et al., 2013). Early vigorous root proliferation may be a useful selection trait for maintaining yield of potato under restricted water level (Puértolas et al., 2014). It is noteworthy to mention that the concept of root ideotype can only be exploited in practical field breeding with a thorough knowledge of the plants stress environment as well as the metabolic cost sustained by the plant to develop and maintain a more vigorous root system (Tuberosa, 2012). In addition to well recognized factors of root density and depth, the hydraulic characteristics of the plant, and its interaction with the soil environment is highly significant in drought adaptation (Vadez, 2014).

\section{Metabolites and Biochemical Response}

$\mathrm{OA}$ is a key drought adaptive mechanism that enables plants to maintain water absorption and cell turgor pressure and thus potentially contribute to sustained higher photosynthetic rate and expansion of growth (Cattivelli et al., 2008). The accumulation of a metabolite during drought does not functionally link with an increase in the tolerance level or with tolerance differences between genotypes. Metabolite levels can increase due to increasing degradation or a reduced biosynthesis of another metabolite without any protective effect (Degenkolbe et al., 2013). The response at metabolic level varies between genotypes and studies have shown differential accumulation of osmotically active solutes. This response to 
stress has also been used as an indicator of drought tolerance in various model plants and crop species (Schafleitner et al., 2007c; Vasquez-Robinet et al., 2008; Evers et al., 2010). Studies in potato have demonstrated that drought stress leads to accumulation of osmotically active solutes including proline, inositol, raffinose, galactinol, and trehalose (Vasquez-Robinet et al., 2008; Evers et al., 2010; Legay et al., 2011; Kondrak et al., 2012) indicating an osmoprotector or osmoregulatory function (Schafleitner et al., 2007a; Teixeira and Pereira, 2007). Proline serves as an ROS scavenger and is used as a non-enzymatic antioxidant to counteract the damaging effect of different ROS members helps in water stress survival through osmoprotection (Vanková et al., 2012). Proline synthesis and catabolism are required for optimal growth at low water potential while its metabolism and function in maintaining a favorable NADP/NADPH ratio are relevant to understanding metabolic adaptations to drought and efforts to enhance drought resistance (Sharma et al., 2011). Proline can act as a signaling molecule to modulate mitochondrial functions, influence cell proliferation or cell death and trigger specific gene expression, which can be essential for plant recovery from stress (Szabados and Savouré, 2010). Similar to metabolic, biochemical response also changes as a function of stress. Win et al. (1991) reported that application of antitranspirants that raised leaf water potential and altering leaf: tuber potential gradients in potato plants subjected to water stress led to greater $\mathrm{Ca}^{2+}$ accumulation in tubers and reversed $\mathrm{Ca}^{2+}$ deficiency-related tuber necrosis. Studies by Lefevre and colleagues showed an increase in the concentration of the majority of analyzed cations in a large number of cultivars in response to water deficits while identifying two cultivars that were able to maintain good yield stability in association with high mineral content under water deficit (Lefevre et al., 2012). Biochemical responses of potato to drought are complex with levels of antioxidants showing increases, decreases, or no effect, depending on the genotype and kind of antioxidant (Andre et al., 2009; Wegener and Jansen, 2013). An increased activity of peroxidase, superoxide dismutase and catalase in response to oxidative stress has been highlighted in potato (Boguszewska et al., 2010) but antioxidant contents of yellow tuber bearing cultivars are weakly affected by the drought treatment as compared to non-yellow tuber bearing types which show high cultivar-dependent variations (Andre et al., 2009).

\section{Harvest Index}

$\mathrm{HI}$ is a key partitioning index that shows the extent of remobilization of photosynthates to tubers. Studies recommend that maintaining a high $\mathrm{HI}$ is the best strategy for improving crop yields under drought stress conditions (Ludlow and Muchow, 1990). Different adaptive mechanisms may associate with growth, biomass partitioning and yield under variable drought stress conditions (McClean et al., 2011). Although, the contrasting responses of the genotypes in response to drought may reflect very distinct evolutionary strategies, change in partitioning to plant parts during early stage of growth is considered as an adaptive response to drought stress of resistant genotypes (Specht et al., 2001; McClean et al., 2011). High HI coupled with high leaf/stem ratio with low number of branches may contribute to achieve high and stable potato yields in drought prone environments (Iwama, 2008; Deguchi et al., 2010) and similarly, identifying genotypes that may use photosynthates for greater tuber expansion at the expense of shoot biomass will help in drought tolerance selection.

\section{Future Research Perspective}

Breeding for drought tolerance presents a challenge as it is a genetically complex polygenic trait with multiple pathways implicated. Success in this objective not only helps in extending the cultivation of crops into drought prone areas but in addition may allow more stable yield under environmental fluctuations. Identifying genetic variation for drought tolerance is the first basic requirement for breeding advancement under drought. An understanding of the genetic architecture of drought resistance components is an important milestone. Effective crop improvement for drought tolerance will require the pyramiding of many disparate characters, with different combinations being appropriate for different growing environments. The difficulty of pyramiding drought tolerance related genes in highly heterozygous tetraploid potato cultivars while considering other important economic traits presents a major challenge with linkage drag and distortion in segregation between inter-specific hybrids presenting further challenges. Hopefully these issues can be circumvented by using biotechnological approaches in future years.

Wild species and adapted germplasm are the reservoir of many useful genes/alleles as they have evolved under natural selection to survive climate extremes (Sharma et al., 2013) and thus evaluation of this material is essential for progress. Considerations should be made in respect to timing and intensity of drought (Chaves et al., 2003; Cattivelli et al., 2008; Coleman, 2008). An understanding of the interaction between below ground water uptake by the roots and above ground water loss from the shoot system is essential and helpful for breeding under different environment scenarios. Figure 3 presents the summarized information on potential adaptive traits under water stress. These traits are principally involved in water uptake and energy translocation and we hold the view that for sustainable management of water stress effect combination of these traits would help in developing stress tolerant varieties in potato. It is crucial to understand the interaction between these agronomical, physiological and morphological traits in order to understand drought tolerance and breed toward sustainability.

An integrated approach is needed where high throughput genotyping can be precisely linked with phenotyping under different field environmental conditions. A lack of precision phenotyping is creating a significant bottleneck to progress. Recent advancement in imaging sensor technology has made it feasible to evaluate stress related traits under field conditions remotely. Infra-red thermography (IRT) has been used as a phenotypic resource for evaluating plant stress (Jones et al., 2009; Prashar et al., 2013) and this needs to be explored using multi-sensor approaches (Furbank and Tester, 2011; Araus and Cairns, 2014). Efficient use of thermography for high-throughput phenotyping (HTP) demands adequate control of variation resulting from the environment and the use of appropriate 


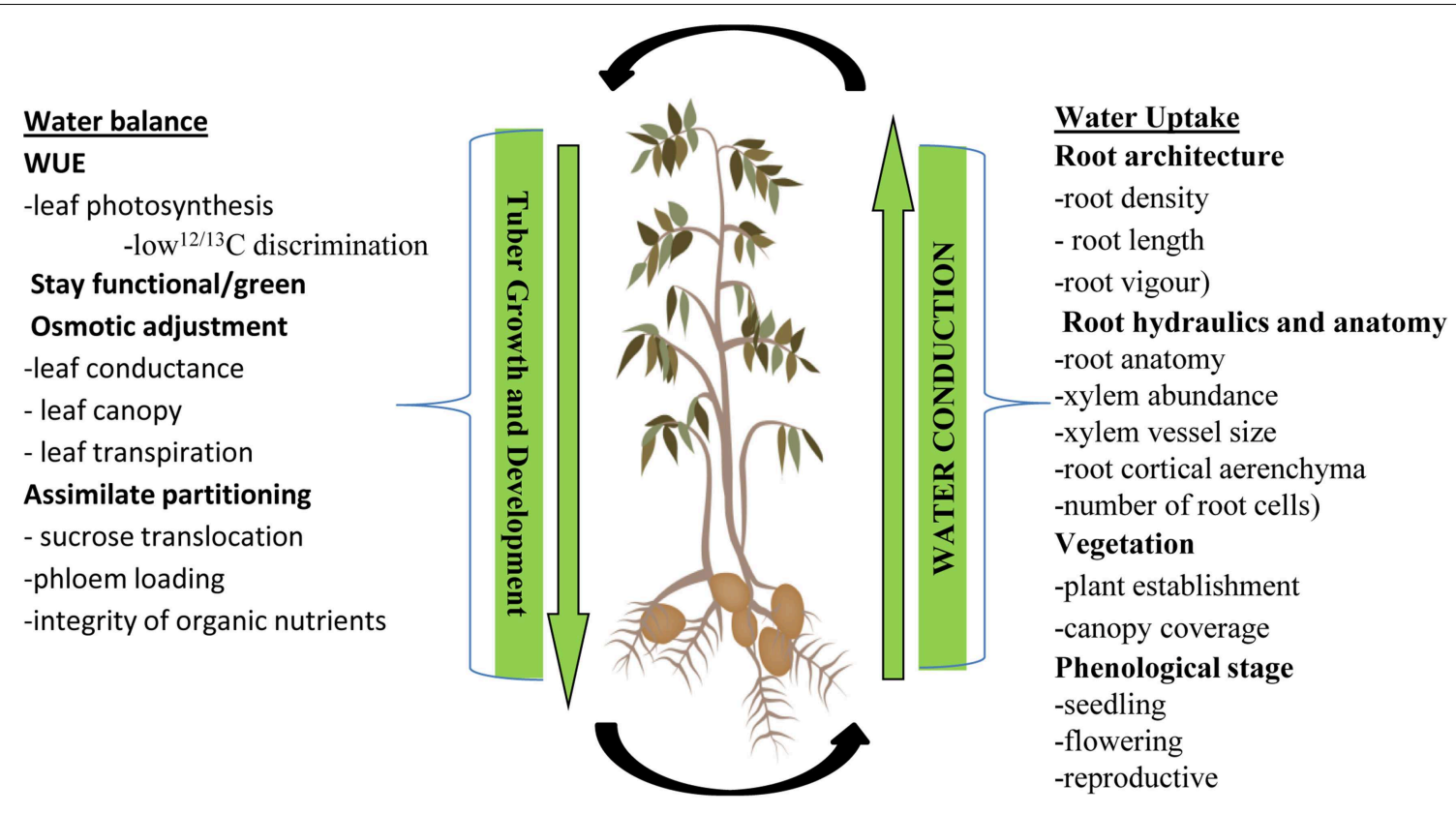

FIGURE 3 | A hypothetical model of morphological and physiological traits implicated during water uptake and balance in drought stressed potato.

normalization techniques (Prashar et al., 2013; Prashar and Jones, 2014). Although IRT combined with effective image analysis provides a powerful approach for comparing large number of genotypes for field scale phenotyping of characters related to plant water relations, a single sensor approach has limitations as complex stress traits are not just influenced by one physiological or morphological component. With IRT providing information on stomatal changes, reflecting WUE, and crop productivity, when used in combination with other available technologies such as fluorescence and hyperspectral imaging it can be more powerful (Chaerle et al., 2009; Furbank and Tester, 2011; Mahlein et al., 2012; Busemeyer et al., 2013; Andrade-Sanchez et al., 2014; Luis Araus and Cairns, 2014) in understanding complex traits such as drought (Topp et al., 2013; Honsdorf et al., 2014). High throughput phenotyping also allows the comprehensive assessment of complex traits by allowing quantitative measurements of the contribution individual parameters. With the new technological advances in HTP methods assessment of three-dimensional characters like plant architecture or plant shape is becoming feasible. As discussed previously, plant architecture and its development provides useful information on plant stress responses and adaptation and their association with yield, thus enabling the linking of high throughput genotyping with high throughput phenotyping both for above and below ground characteristics (Dhondt et al., 2013; Chen et al., 2014; Deery et al., 2014; Paulus et al., 2014).

Along with effective analysis and reproducibility for high throughput phenotyping, the other major requirement for drought field phenotyping is to have adequate water stress conditions and achieving proper control over the field stress environment in order to assure relevant drought test profile
(Tuberosa, 2012). It is therefore imperative that researchers should select ideal drought prone regions with limiting rainfall or irrigation distributed over a reasonable time frame. Artificial drought control with rain-out shelters can also be helpful. Experimental protocols involving field and control environment should complement each other as some physiological traits are better exploited in either situation. The importance of understanding the replication and repeatability of the results under field conditions is essential to characterize the effects of QTLs and to evaluate stability in diverse environment and breed for different conditions and different scenarios of stress interaction (Cattivelli et al., 2008). Analysis of G $\times \mathrm{E}$ (genotype $\times$ environment), which is becoming very common, should be incorporated with management $(M)$ in any controlled and field experiment for identifying genotypes for specific environment and under specific management practices system $(G \times E \times M)$ to overcome issues relating to stress traits.

The candidate gene strategy bridges the division between quantitative and molecular genetics in studying complex drought stress responses and has been gainfully applied to rice and barley drought tolerance (Nguyen et al., 2004; Tondelli et al., 2006). Comparative omics analysis on stress-responsive epigenomes could aid in understanding of drought adaptations. Transgenic research effort should focus on conferring drought tolerance while increasing or stabilizing tuber yield. This implies that drought transgenics should have extensive root system, reduced stomata density and high WUE while possessing higher levels of $\mathrm{ABA}$, proline, soluble sugar, reacting oxygen species-scavenging enzyme activities during drought stress (Werner et al., 2010; Yu et al., 2013). Transgenic approaches should play a role in the future in developing drought tolerant potato cultivars 
with incorporation of specific cloned genes and restricting the transfer of undesirable genes from donor organism (Ashraf, 2010). Similarly, use of emerging genome engineering techniques like a RNA-guided endonuclease technology for sequencespecific gene expression known as clustered regularly interspaced short palindromic repeats (CRISPR) provides a simple approach for selectively perturbing gene expression on a genome-wide scale (Sander and Joung, 2014). As stress traits are complex traits, approaches like gene pyramiding not only for stress combinations but also specific stress can be targeted with cautious (Ashraf, 2010). This approach has led to engineering genes that encode compatible organic osmolytes, plant growth regulators, antioxidants, heat shock proteins, and TFs involved in gene expression in potato (Stiller et al., 2008; Shin et al., 2011; Zhang et al., 2011; Kondrak et al., 2012; Cheng et al., 2013; Pal et al., 2013; Pieczynski et al., 2013). Transgenics can be used to their full potential with the lifting of legislative barriers in many countries so as to provide opportunities for extensive field testing in different environments.

The plant root system can act as "resource island" which attracts and selects specific microbial communities that can promote plant growth through enhancement of plant photosynthetic activity and biomass synthesis under water deficit (Ruiz-Sanchez et al., 2011; Marasco et al., 2012; Naveed et al., 2014). Studies have demonstrated the potential of arbuscular mycorrhizal (AM) symbiosis in developing drought tolerant maize and sweet potato cultivars respectively (Boomsma and Vyn, 2008; Naher et al., 2013). AM enhanced the adaptation of sweet potato plants to drought stress as indicated by higher values of leaf RWC, root dry weight, root length, transpiration, and WUE as compared to non-AM plants (Naher et al., 2013). These microorganisms offer great potential because the resulting tolerance/adaptability could be ascribed to changes in soil microbial community rather than genetic changes in plants. For example, soil microbes can prime plants to increase drought resistance compounds or elicitors more rapidly and thus increase resistance to stress (Horn et al., 2013; Okamoto et al., 2013). However, the ability of crops to take advantage of soil microorganism induced drought tolerance may be hindered by modern agricultural practices that reduce crop-soil interactions (Bennett et al., 2013).

A holistic approach involving morphological, physiological, biochemical, phonological, and anatomical responses to water stress conditions should provide the best opportunities for enhancing drought tolerance in the potato crop. Concerted efforts are required by geneticists, physiologists, breeders, agronomists, and technologists toward precise and accurate

\section{References}

Agoston, B. S., Kovács, D., Tompa, P., and Perczel, A. (2011). Full backbone assignment and dynamics of the intrinsically disordered dehydrin ERD14. Biomol. NMR Assign. 5, 189-193. doi: 10.1007/s12104-011-9297-2

Albiski, F., Najla, S., Sanoubar, R., Alkabani, N., and Murshed, R. (2012). In vitro screening of potato lines for drought tolerance. Physiol. Mol. Bio. Plants 18, 315-321. doi: 10.1007/s12298-012-0127-5 phenotypic evaluations and the development of platforms for the automated analysis of the necessarily large mapping populations. This will ensure good monitoring and phenotyping of physiological, morphological, and growth parameters under water stress. Identification of more potato phenotypes that correlate positively with drought performance in the field is urgently needed. It is noteworthy to mention that different environmental conditions in different potato growing regions demand diverse options and there is a lot to learn and gain from their interactions with the complex nature of the trait.

\section{Conclusion}

One of the great challenges for the next decade is to mitigate any effect of climate change on crop production with a main focus being to maintain crop production levels with reduced availability of water. A multi-pronged approach using combined expertise will be critical in sustaining potato production. Efforts need to be intensified to improve the database of potato drought-related genes and our understanding of their potential roles in drought responses. Natural variation in wild and cultivated potato germplasm provides an excellent platform for the discovery of diagnostic markers for markerassisted selection (MAS) and for cloning and insertion of drought resistance genes applicable to diverse agrarian zones. Although genetic manipulation, using key genes identified from functional studies, offers significant opportunities for the development of drought tolerant varieties it will be necessary to ensure that any deleterious negative effects are avoided. The emergence of novel approaches involving the use of high throughput "omics" technologies (also known as "Phenomics") including genetic, physiological, biochemical, molecular and biotechnological techniques offer hope for exciting innovations toward maintaining food and income security, mitigation of poverty, and reduction of farmers' risk in vulnerable agricultural environments.

\section{Acknowledgments}

This review was compiled under the Marie Curie fellowship granted to the first author JEO by the European Union. We gratefully acknowledge the financial support of the Scottish Government and thank colleagues at The James Hutton Institute for critical reviewing of the manuscript. The National Root Crops Research Institute Umudike, Nigeria, is gratefully acknowledged for their support. 
a hot climate. J. Agron. Crop Sci. 176, 119-129. doi: 10.1111/j.1439037X.1996.tb00454.x

Ambrosone, A., Costa, A., Martinelli, R., Massarelli, I., De Simone, V., Grillo, S., et al. (2011). Differential gene regulation in potato cells and plants upon abrupt or gradual exposure to water stress. Acta Physiol. Plant. 33, 1157-1171. doi: 10.1007/s11738-010-0644-1

Ambrosone, A., Di Giacomo, M., Leone, A., Grillo, M. S., and Costa, A. (2013). Identification of early induced genes upon water deficit in potato cell cultures by cDNA-AFLP. J. Plant Res. 126, 169-178. doi: 10.1007/s10265-0120505-7

Andrade-Sanchez, P., Gore, M. A., Heun, J. T., Thorp, K. R., Carmo-Silva, A. E., French, A. N., et al. (2014). Development and evaluation of a field-based high-throughput phenotyping platform. Funct. Plant Biol. 41, 68-79. doi: 10.1071/FP13126

Andre, C. M., Schafleitner, R., Guignard, C., Oufir, M., Alvarado Aliaga, C. A., Nomberto, G., et al. (2009). Modification of the health-promoting value of potato tubers field grown under drought stress: emphasis on dietary antioxidant and glycoalkaloid contents in five native andean cultivars (Solanum tuberosum L.). J. Agric. Food Chem. 57, 599-609. doi: 10.1021/jf8025452

Angelopoulos, K., Dichio, B., and Xiloyannis, C. (1996). Inhibition of photosynthesis in olive trees (Olea europaea L) during water stress and rewatering. J. Exp. Bot. 47, 1093-1100. doi: 10.1093/jxb/47.8.1093

Anithakumari, A. M., Dolstra, O., Vosman, B., Visser, R. G. F., and van der Linden, C. G. (2011). In vitro screening and QTL analysis for drought tolerance in diploid potato. Euphytica 181, 357-369. doi: 10.1007/s10681-011-0446-6

Anithakumari, A. M., Nataraja, K. N., Visser, R. G. F., and Van Der Linden, C. G. (2012). Genetic dissection of drought tolerance and recovery potential by quantitative trait locus mapping of a diploid potato population. Mol. Breed. 30, 1413-1429. doi: 10.1007/s11032-012-9728-5

Araus, J. L., Amaro, T., Voltas, J., Nakkoul, H., and Nachit, M. M. (1998). Chlorophyll fluorescence as a selection criterion for grain yield in durum wheat under Mediterranean conditions. Field Crops Res. 55, 209-223. doi: 10.1016/S0378-4290(97)00079-8

Araus, J. L., and Cairns, J. E. (2014). Field high-throughput phenotyping: the new crop breeding frontier. Trends Plant Sci. 19, 52-61. doi: 10.1016/j.tplants.2013.09.008

Araus, J. L., Serret, M. D., and Edmeades, G. O. (2012). Phenotyping maize for adaptation to drought. Front. Physiol. 3:305. doi: 10.3389/fphys.2012.00305

Ashraf, M. (2010). Inducing drought tolerance in plants: recent advances. Biotechnol. Adv. 28, 169-183. doi: 10.1016/j.biotechadv.2009.11.005

Ashraf, M., and Harris, P. J. C. (2013). Photosynthesis under stressful environments: an overview. Photosynthetica 51, 163-190. doi: 10.1007/s11099013-0021-6

Auber, J., Bonierbale, M., and Asch, F. (2013). "Screening potato for drought tolerance by linking physiological to morphological traits. Agricultural development within the rural-urban continuum," in Tropentag (Stuttgart: Hohenheim).

Baker, E. H., Bradford, K. J., Bryant, J. A., and Rost, T. L. (1995). A comparison of desiccation-related proteins (dehydrin and QP47) in peas (Pisum sativum). Seed Sci. Res. 5, 185-193. doi: 10.1017/S0960258500002841

Baker, N. R. (2008). Chlorophyll fluorescence: a probe of photosynthesis in vivo. Annu. Rev. Plant Biol. 59, 89-113. doi: 10.1146/annurev.arplant.59.032607. 092759

Baker, N. R., and Bowyer, J. R. (1994). Photoinhibition of Photosynthesis: From Molecular Mechanisms to the Field. Oxford: Bios Scientific Publishers.

Baker, N., and Horton, P. (1987). Chlorophyll fluorescence quenching during photoinhibition. Photoinhibition 9, 145-168.

Balasimha, D., and Virk, M. S. (1978). Effect of water stress on tuber yield and metabolism in potato. J. Ind. Potato Assoc. 5, 104-107.

Barriopedro, D., Fischer, E. M., Luterbacher, J., Trigo, R., and GarciaHerrera, R. (2011). The hot summer of 2010: redrawing the temperature record map of Europe. Science 332, 220-224. doi: 10.1126/science. 1201224

Bennett, A. E., Daniell, T. J., and White, P. J. (2013). "Benefits of breeding crops for yield response to soil organisms," in Molecular Microbial Ecology of the Rhizosphere, ed F. J. de Bruijn (Hoboken, NJ: John Wiley \& Sons, Inc.), 17-27.

Birch, P. R. J., Bryan, G., Fenton, B., Gilroy, E. M., Hein, I., Jones, J. T., et al. (2012). Crops that feed the world 8: potato: are the trends of increased global production sustainable? Food Secur. 4, 477-508. doi: 10.1007/s12571-0120220-1

Blackman, C. J., Brodribb, T. J., and Jordan, G. J. (2009). Leaf hydraulics and drought stress: response, recovery and survivorship in four woody temperate plant species. Plant Cell Environ. 32, 1584-1595. doi: 10.1111/j.13653040.2009.02023.x

Blum, A. (2009). Effective use of water (EUW) and not water-use efficiency (WUE) is the target of crop yield improvement under drought stress. Field Crops Res. 112, 119-123. doi: 10.1016/j.fcr.2009.03.009

Blum, A. (2011). Drought resistance - is it really a complex trait? Funct. Plant Biol. 38, 753-757. doi: 10.1071/FP11101

Blum, A., and Arkin, G. F. (1984). Sorghum root-growth and water-use as affected by water-supply and growth duration. Field Crops Res. 9, 131-142. doi: 10.1016/0378-4290(84)90019-4

Boguszewska, D., Grudkowska, M., and Zagdanska, B. (2010). Drought-responsive antioxidant enzymes in potato (Solanum tuberosum L.). Potato Res. 53, 373-382. doi: 10.1007/s11540-010-9178-6

Boomsma, C. R., and Vyn, T. J. (2008). Maize drought tolerance: potential improvements through arbuscular mycorrhizal symbiosis? Field Crops Res. 108, 14-31. doi: 10.1016/j.fcr.2008.03.002

Boyer, J. S. (1976). Photosynthesis at low water potentials. Philos. Trans. R. Soc. Lond. B Biol. Sci. 273, 501-512. doi: 10.1098/rstb.1976.0027

Buerling, K., Cerovic, Z. G., Cornic, G., Ducruet, J.-M., Noga, G., and Hunsche, M. (2013). Fluorescence-based sensing of drought-induced stress in the vegetative phase of four contrasting wheat genotypes. Environ. Exp. Bot. 89, 51-59. doi: 10.1016/j.envexpbot.2013.01.003

Busemeyer, L., Mentrup, D., Moeller, K., Wunder, E., Alheit, K., Hahn, V., et al. (2013). BreedVision - A multi-sensor platform for non-destructive field-based phenotyping in plant breeding. Sensors 13, 2830-2847. doi: 10.3390/s130302830

Büssis, D., and Heineke, D. (1998). Acclimation of potato plants to polyethylene glycol-induced water deficit II. Contents and subcellular distribution of organic solutes. J. Exp. Bot. 49, 1361-1370. doi: 10.1093/jxb/49.325.1361

Caird, M. A., Richards, J. H., and Hsiao, T. C. (2007). Significant transpirational water loss occurs throughout the night in field-grown tomato. Funct. Plant Biol. 34, 172-177. doi: 10.1071/FP06264

Camire, M. E., Kubow, S., and Donnelly, D. J. (2009). Potatoes and human health. Crit. Rev. Food Sci. Nutr. 49, 823-840. doi: 10.1080/10408390903041996

Cattivelli, L., Rizza, F., Badeck, F.-W., Mazzucotelli, E., Mastrangelo, A. M., Francia, E., et al. (2008). Drought tolerance improvement in crop plants: an integrated view from breeding to genomics. Field Crops Res. 105, 1-14. doi: 10.1016/j.fcr.2007.07.004

Chaerle, L., and van der Straeten, D. (2000). Imaging techniques and the early detection of plant stress. Trends Plant Sci. 5, 495-501. doi: 10.1016/S13601385(00)01781-7

Chaerle, L., Lenk, S., Leinonen, I., Jones, H. G., Van Der Straeten, D., and Buschmann, C. (2009). Multi-sensor plant imaging: towards the development of a stress-catalogue. Biotechnol. J. 4, 1152-1167. doi: 10.1002/biot.200800242

Chaves, M. M. (1991). Effects of water deficits on carbon assimilation. J. Exp. Bot. 42, 1-16. doi: 10.1093/jxb/42.1.1

Chaves, M. M., Maroco, J. P., and Pereira, J. S. (2003). Understanding plant responses to drought - from genes to the whole plant. Funct. Plant Biol. 30, 239-264. doi: 10.1071/FP02076

Chaves, M. M., Pereira, J. S., Maroco, J., Rodrigues, M. L., Ricardo, C. P. P., Osorio, M. L., et al. (2002). How plants cope with water stress in the field. Photosynthesis and growth. Ann. Bot. 89, 907-916. doi: 10.1093/aob/mcf105

Chen, D., Neumann, K., Friedel, S., Kilian, B., Chen, M., Altmann, T., et al. (2014). Dissecting the phenotypic components of crop plant growth and drought responses based on high-throughput image analysis. Plant Cell. 26, 4636-4655. doi: $10.1105 /$ tpc.114.129601

Chen, Z., Cuin, T. A., Zhou, M., Twomey, A., Naidu, B. P., and Shabala, S. (2007). Compatible solute accumulation and stress-mitigating effects in barley genotypes contrasting in their salt tolerance. J. Exp. Bot. 58, 4245-4255. doi: 10.1093/jxb/erm284

Cheng, Y.-J., Deng, X.-P., Kwak, S.-S., Chen, W., and Eneji, A. E. (2013). Enhanced tolerance of transgenic potato plants expressing choline oxidase in chloroplasts against water stress. Bot. Stud. 54, 30-38. doi: 10.1186/1999-3110-54-30

Clavel, D., Diouf, O., Khalfaoui, J. L., and Braconnier, S. (2006). Genotypes variations in fluorescence parameters among closely related groundnut 
(Arachis hypogaea L.) lines and their potential for drought screening programs. Field Crops Res. 96, 296-306. doi: 10.1016/j.fcr.2005.07.012

Coleman, W. K. (1986). Water relations of the potato (Solanum tuberosum L.) cultivars Raritan and Shepody. Am. Potato J. 63, 263-276. doi: 10.1007/BF02852938

Coleman, W. K. (2008). Evaluation of wild Solanum species for drought resistance: 1. Solanum gandarillasii Cardenas. Environ. Exp. Bot. 62, 221-230. doi: 10.1016/j.envexpbot.2007.08.007

Condon, A. G., Richards, R. A., Rebetzke, G. J., and Farquhar, G. D. (2002). Improving intrinsic water-use efficiency and crop yield, Presented at the 1999 CSSA Symposium on Water Use Efficiency, organized by Div. C-2 chair, Dr. Tom Gerik. Crop Sci. 42, 122-131. doi: 10.2135/cropsci2002.0122

Condon, A., Farquhar, G., and Richards, R. (1990). Genotypic variation in carbon isotope discrimination and transpiration efficiency in wheat. Leaf Gas Exchange and Whole Plant Studies. Funct. Plant Biol. 17, 9-22. doi: 10.1071/ pp9900009

Cook, E. R., Seager, R., Cane, M. A., and Stahle, D. W. (2007). North American drought: reconstructions, causes, and consequences. Earth Sci. Rev. 81, 93-134. doi: 10.1016/j.earscirev.2006.12.002

Cornic, G., Prioul, J. L., and Louason, G. (1983). Stomatal and non-stomatal contribution in the decline in leaf net co2 uptake during rapid water-stress. Physiol. Plant. 58, 295-301. doi: 10.1111/j.1399-3054.1983.tb04184.x

Crusciol, C. A. C., Pulz, A. L., Lemos, L. B., Soratto, R. P., and Lima, G. P. P. (2009). Effects of silicon and drought stress on tuber yield and leaf biochemical characteristics in potato. Crop Sci. 49, 949-954. doi: $10.2135 /$ cropsci2008.04.0233

Cruz de Carvalho, M. H. (2008). Drought stress and reactive oxygen species: production, scavenging and signaling. Plant Signal. Behav. 3, 156-165. doi: 10.4161/psb.3.3.5536

Czyczylo-Mysza, I., Marcinska, I., Skrzypek, E., Chrupek, M., Grzesiak, S., Hura, T., et al. (2011). Mapping QTLs for yield components and chlorophyll a fluorescence parameters in wheat under three levels of water availability. Plant Genet. Resour. Charact. Util. 9, 291-295. doi: 10.1017/S1479262111 000207

Dallacosta, L., Dellevedove, G., Gianquinto, G., Giovanardi, R., and Peressotti, A. (1997). Yield, water use efficiency and nitrogen uptake in potato: influence of drought stress. Potato Res. 40, 19-34. doi: 10.1007/ BF02407559

Das, K., Pradhan, T., Ghosh, S., and Mishra, B. K. (2005). Evaluation of drought resistance characteristics of upland rice cultivars. Oryza 42, 138-144.

Davies, W. J., and Zhang, J. H. (1991). Root signals and the regulation of growth and development of plants in drying soil. Annu. Rev. Plant Physiol. Plant Mol. Biol. 42, 55-76. doi: 10.1146/annurev.pp.42.060191.000415

Davies, W. J., Wilkinson, S., and Loveys, B. (2002). Stomatal control by chemical signalling and the exploitation of this mechanism to increase water use efficiency in agriculture. New Phytol. 153, 449-460. doi: 10.1046/j.0028646X.2001.00345.X

Deblonde, P. M. K., and Ledent, J. F. (2001). Effects of moderate drought conditions on green leaf number, stem height, leaf length and tuber yield of potato cultivars. Eur. J. Agron. 14, 31-41. doi: 10.1016/S1161-0301(00)00081-2

Deblonde, P. M. K., Haverkort, A. J., and Ledent, J. F. (1999). Responses of early and late potato cultivars to moderate drought conditions: agronomic parameters and carbon isotope discrimination. Eur. J. Agron. 11, 91-105. doi: 10.1016/S1161-0301(99)00019-2

Deery, D., Jimenez-Berni, J., Jones, H., Sirault, X., and Furbank, R. (2014). Proximal remote sensing buggies and potential applications for field-based phenotyping. Agronomy 4, 349-379. doi: 10.3390/agronomy4030349

Degenkolbe, T., Do, P. T., Kopka, J., Zuther, E., Hincha, D. K., and Koehl, K. I. (2013). Identification of drought tolerance markers in a diverse population of rice cultivars by expression and metabolite profiling. PLoS ONE 8:e63637. doi: 10.1371/journal.pone.0063637

Deguchi, T., Naya, T., Wangchuk, P., Itoh, E., Matsumoto, M., Zheng, X., et al. (2010). Aboveground characteristics, yield potential and drought tolerance in "Konyu" potato cultivars with large root mass. Potato Res. 53, 331-340. doi: 10.1007/s11540-010-9174-x

Dhondt, S., Wuyts, N., and Inzé, D. (2013). Cell to whole-plant phenotyping: the best is yet to come. Trends Plant Sci. 18, 428-439. doi: 10.1016/j.tplants.2013.04.008
Dodd, I. C. (2005). Root-to-shoot signalling: assessing the roles of "up" in the up and down world of long-distance signalling in planta. Plant Soil 274, 251-270. doi: 10.1007/s11104-004-0966-0

Du, H., Liu, H., and Xiong, L. (2013). Endogenous auxin and jasmonic acid levels are differentially modulated by abiotic stresses in rice. Front. Plant Sci. 4:397. doi: 10.3389/fpls.2013.00397

Ekanayake, I. J., and Midmore, D. J. (1992). Genotypic variation for root pulling resistance in potato and its relationship with yield under water-deficit stress. Euphytica 61, 43-53. doi: 10.1007/BF00035545

Eldredge, E., Holmes, Z., Mosley, A., Shock, C., and Stieber, T. (1996). Effects of transitory water stress on potato tuber stem-end reducing sugar and fry color. Am. Potato J. 73, 517-530. doi: 10.1007/BF02851697

Elsharkawy, M. A., Hernandez, A. D., and Hershey, C. (1992). Yield stability of cassava during prolonged mid-season water-stress. Exp. Agric. 28, 165-174. doi: $10.1017 /$ S0014479700019608

Eltayeb, A. E., Yamamoto, S., Habora, M. E. E., Yin, L., Tsujimoto, H., and Tanaka, K. (2011). Transgenic potato overexpressing Arabidopsis cytosolic AtDHAR1 showed higher tolerance to herbicide, drought and salt stresses. Breed. Sci. 61, 3-10. doi: 10.1270/jsbbs.61.3

Evers, D., Lefevre, I., Legay, S., Lamoureux, D., Hausman, J.-F., Rosales, R. O. G., et al. (2010). Identification of drought-responsive compounds in potato through a combined transcriptomic and targeted metabolite approach. J. Exp. Bot. 61, 2327-2343. doi: 10.1093/jxb/erq060

Fanourakis, D., Carvalho, S. M. P., Almeida, D. P. F., and Heuvelink, E. (2011). Avoiding high relative air humidity during critical stages of leaf ontogeny is decisive for stomatal functioning. Physiol. Plant. 142, 274-286. doi: 10.1111/j.1399-3054.2011.01475.x

FAO. (2011). Food and Agricultural Organization of the United Nations Database. Rome.

Farooq, M., Wahid, A., Kobayashi, N., Fujita, D., and Basra, S. M. A. (2009). Plant drought stress: effects, mechanisms and management. Agron. Sustain. Dev. 29, 185-212. doi: 10.1051/agro:2008021

Farquhar, G. D., and Richards, R. A. (1984). Isotopic composition of plant carbon correlates with water-use efficiency of wheat genotypes. Aust. J. Plant Physiol. 11, 539-552. doi: 10.1071/PP9840539

Farquhar, G. D., Ehleringer, J. R., and Hubick, K. T. (1989). Carbon isotope discrimination and photosynthesis. Annu. Rev. Plant Physiol. Plant Mol. Biol. 40, 503-537. doi: 10.1146/annurev.pp.40.060189.002443

Fasan, T., and Haverkort, A. J. (1991). The influence of cyst nematodes and drought on potato growth.1. Effects on plant-growth under semicontrolled conditions. Neth. J. Plant Pathol. 97, 151-161. doi: 10.1007/ BF01995964

Fatemy, F., and Evans, K. (1986). Effects of Globodera rostochiensis and water stress on shoot and root growth and nutrient uptake of potatoes. Rev. Nematol. 9, 181-184.

Faver, K. L., Gerik, T. J., Thaxton, P. M., and Elzik, K. M. (1996). Late season water stress in cotton.2. Leaf gas exchange and assimilation capacity. Crop Sci. 36, 922-928. doi: 10.2135/cropsci1996.0011183X0036000 $40018 \mathrm{x}$

Fischlin, A., Midgley, G. F., Price, J., Leemans, R., Gopal, B., Turley, C., et al. (2007). "Ecosystems, their properties, goods, and services," in Climate Change 2007: Impacts, Adaptation and Vulnerability. Contribution of Working Group II to the Fourth Assessment Report of the Intergovernmental Panel on Climate Change, eds M. L. Parry, O. F. Canziani, J. P. Palutikof, P. J. van der Linden, and C. E. Hanson (Cambridge: Cambridge University Press), 211-272.

Fleisher, D. H., Barnaby, J., Sicher, R., Resop, J. P., Timlin, D. J., and Reddy, V. R. (2013). Effects of elevated CO2 and cyclic drought on potato under varying radiation regimes. Agric. For. Meteorol. 171, 270-280. doi: 10.1016/j.agrformet.2012.12.011

Food and Agriculture Organization of the United Nations. (2009). New Light on a Hidden Treasure. Rome: Food and Agriculture Organization of the United Nations.

Fracheboud, Y., Jompuk, C., Ribaut, J. M., Stamp, P., and Leipner, J. (2004). Genetic analysis of cold-tolerance of photosynthesis in maize. Plant Mol. Biol. 56, 241-253. doi: 10.1007/s11103-004-3353-6

Frusciante, L., Barone, A., Carputo, D., and Ranalli, P. (1999). Breeding and physiological aspects of potato cultivation in the Mediterranean region. Potato Res. 42, 265-277. doi: 10.1007/BF02357857 
Furbank, R. T., and Tester, M. (2011). Phenomics - technologies to relieve the phenotyping bottleneck. Trends Plant Sci. 16, 635-644. doi: 10.1016/j.tplants.2011.09.005

GAIN. (2010). Global Agricultural Information Network of the USDA Foreign Agricultural Service. GAIN Report No RS1060.

Gastelo, M., Kleinwechter, U., and Bonierbale, M. (2014). Global Potato Research for a Changing World. Working Paper. Available online at: http://cipotato.org/ wp-content/uploads/2014/06/006151.pdf.

Genty, B., Briantais, J. M., and Dasilva, J. B. V. (1987). Effects of drought on primary photosynthetic processes of cotton leaves. Plant Physiol. 83, 360-364. doi: $10.1104 /$ pp.83.2.360

Germ, M., Kreft, I., Stibilj, V., and Urbanc-Bericic, O. (2007). Combined effects of selenium and drought on photosynthesis and mitochondrial respiration in potato. Plant Physiol. Biochem. 45, 162-167. doi: 10.1016/j.plaphy.2007.01.009

Gimenez, C., Mitchell, V. J., and Lawlor, D. W. (1992). Regulation of photosynthetic rate of 2 sunflower hybrids under water-stress. Plant Physiol. 98, 516-524. doi: 10.1104/pp.98.2.516

Golldack, D., Li, C., Mohan, H., and Probst, N. (2014). Tolerance to drought and salt stress in plants: unraveling the signaling networks. Front. Plant Sci. 5:151. doi: $10.3389 /$ fpls.2014.00151

Grant, O. M., Tronina, L., Jones, H. G., and Chaves, M. M. (2007). Exploring thermal imaging variables for the detection of stress responses in grapevine under different irrigation regimes. J. Exp. Bot. 58, 815-825. doi: $10.1093 / \mathrm{jxb} / \mathrm{erl} 153$

Gregory, P., and Simmonds, L. (1992). "Water relations and growth of potatoes," in The Potato Crop, ed P. M. Harris (London: Springer), 214-246.

Guo, S.-W., Zhou, Y., Song, N., and Shen, Q.-R. (2006). Some physiological processes related to water use efficiency of higher plants. Agric. Sci. China 5, 403-411. doi: 10.1016/S1671-2927(06)60068-0

Hanin, M., Brini, F., Ebel, C., Toda, Y., Takeda, S., and Masmoudi, K. (2011). Plant dehydrins and stress tolerance: versatile proteins for complex mechanisms. Plant Signal. Behav. 6, 1503-1509. doi: 10.4161/psb.6.10.17088

Haverkort, A. J., and Verhagen, A. (2008). Climate change and its repercussions for the potato supply chain. Potato Res. 51, 223-237. doi: 10.1007/s11540-0089107-0

Haverkort, A. J., Fasan, T., and Vandewaart, M. (1991). The influence of cyst nematodes and drought on potato growth. 2. Effects on plant water relations under semi-controlled conditions. Neth. J. Plant Pathol. 97, 162-170. doi: 10.1007/BF01995965

Haverkort, A. J., Vandewaart, M., and Bodlaender, K. B. A. (1990). The effect of early drought stress on numbers of tubers and stolons of potato in controlled and field conditions. Potato Res. 33, 89-96. doi: 10.1007/BF02358133

Heuer, B., and Nadler, A. (1998). Physiological response of potato plants to soil salinity and water deficit. Plant Sci. 137, 43-51. doi: 10.1016/S01689452(98)00133-2

Hey, S. J., Byrne, E., and Halford, N. G. (2010). The interface between metabolic and stress signalling. Ann. Bot. 105, 197-203. doi: 10.1093/aob/mcp285

Hijmans, R. J. (2003). The effect of climate change on global potato production. Am. J. Potato Res. 80, 271-279. doi: 10.1007/BF02855363

Holden, N., Brereton, A., Fealy, R., and Sweeney, J. (2003). Possible change in Irish climate and its impact on barley and potato yields. Agric. For. Meteor. 116, 181-196. doi: 10.1016/S0168-1923(03)00002-9

Honsdorf, N., March, T. J., Berger, B., Tester, M., and Pillen, K. (2014). Highthroughput phenotyping to detect drought tolerance QTL in wild barley introgression lines. PLoS ONE 9:e97047. doi: 10.1371/journal.pone.0097047

Horie, T., Matsuura, S., Takai, T., Kuwasaki, K., Ohsumi, A., and Shiraiwa, T. (2006). Genotypic difference in canopy diffusive conductance measured by a new remote-sensing method and its association with the difference in rice yield potential. Plant Cell Environ. 29, 653-660. doi: 10.1111/j.13653040.2005.01445.x

Horn, R., Chudobova, I., Haensel, U., Herwartz, D., Von Koskull-Doering, P., and Schillberg, S. (2013). Simultaneous treatment with tebuconazole and abscisic acid induces drought and salinity stress tolerance in Arabidopsis thaliana by maintaining key plastid protein levels. J. Proteome Res. 12, 1266-1281. doi: 10.1021/pr300931u

Horton, P., Ruban, A., and Walters, R. (1996). Regulation of light harvesting in green plants. Annu. Rev. Plant Biol. 47, 655-684. doi: 10.1146/annurev.arplant.47.1.655
Hsiao, T. C. (1973). Plant responses to water stress. Annu. Rev. Plant Physiol. 24 519-570. doi: 10.1146/annurev.pp.24.060173.002511

Hwang, E.-W., Shin, S.-J., Park, S.-C., Jeong, M.-J., and Kwon, H.-B. (2011a). Identification of miR172 family members and their putative targets responding to drought stress in Solanum tuberosum. Genes Genomics 33, 105-110. doi: 10.1007/s13258-010-0135-1

Hwang, E.-W., Shin, S.-J., Yu, B.-K., Byun, M.-O., and Kwon, H.-B. (2011b). miR171 family members are involved in drought response in Solanum tuberosum. J. Plant Biol. 54, 43-48. doi: 10.1007/s12374-010-9141-8

Ierna, A., and Mauromicale, G. (2006). Physiological and growth response to moderate water deficit of off-season potatoes in a Mediterranean environment. Agric. Water Manag. 82, 193-209. doi: 10.1016/j.agwat.2005.05.005

Ierna, A., Pandino, G., Lombardo, S., and Mauromicale, G. (2011). Tuber yield, water and fertilizer productivity in early potato as affected by a combination of irrigation and fertilization. Agric. Water Manag. 101, 35-41. doi: 10.1016/j.agwat.2011.08.024

Impa, S. M., Nadaradjan, S., Boominathan, P., Shashidhar, G., Bindumadhava, H., and Sheshshayee, M. S. (2005). Carbon isotope discrimination accurately reflects variability in WUE measured at a whole plant level in rice. Crop Sci. 45, 2517-2522. doi: 10.2135/cropsci2005.0119

Iwama, K., and Yamaguchi, J. (2006). "Abiotic stresses," in Handbook of Potato Production, Improvement and Postharvest Management, eds J. Gopal and S. M. Khurana (New York, NY: Food Product Press), 231-278.

Iwama, K. (2008). Physiology of the potato: new insights into root system and repercussions for crop management. Potato Res. 51, 333-353. doi: 10.1007/s11540-008-9120-3

Jackson, R. B., Sperry, J. S., and Dawson, T. E. (2000). Root water uptake and transport: using physiological processes in global predictions. Trends Plant Sci. 5, 482-488. doi: 10.1016/S1360-1385(00)01766-0

Jackson, R. D., Idso, S. B., Reginato, R. J., and Pinter, P. J. (1981). Canopy temperature as a crop water-stress indicator. Water Resour. Res. 17, 1133-1138. doi: 10.1029/WR017i004p01133

Jefferies, R. A. (1992). Effects of drought on chlorophyll fluorescence in potato (Solanum tuberosum L.). 2. Relations between plant-growth and measurements of fluorescence. Potato Res. 35, 35-40. doi: 10.1007/BF02357720

Jefferies, R. A. (1993a). Cultivar responses to water-stress in potato: effects of shoot and roots. New Phytol. 123, 491-498. doi: 10.1111/j.1469-8137.1993.tb03761.x

Jefferies, R. A. (1993b). Responses of potato genotypes to drought. 1. Expansion of individual leaves and osmotic adjustment. Ann. Appl. Biol. 122, 93-104. doi: 10.1111/j.1744-7348.1993.tb04017.x

Jefferies, R. A. (1994). Drought and chlorophyll fluorescence in field-grown potato (Solanum tuberosum). Physiol. Plant. 90, 93-97. doi: 10.1111/j.13993054.1994.tb02197.x

Jefferies, R. A., and Mackerron, D. K. L. (1987). Aspects of the physiologicalbasis of cultivar differences in yield of potato under droughted and irrigated conditions. Potato Res. 30, 201-217. doi: 10.1007/BF02357663

Jefferies, R. A., and Mackerron, D. K. L. (1989). Radiation interception and growth of irrigated and droughted potato (Solanum tuberosum). Field Crops Res. 22, 101-112. doi: 10.1016/0378-4290(89)90061-0

Jefferies, R. A., and Mackerron, D. K. L. (1993). Responses of potato genotypes to drought. 2. Leaf-area index, growth and yield. Ann. Appl. Biol. 122, 105-112. doi: 10.1111/j.1744-7348.1993.tb04018.x

Jia, W., and Zhang, J. (2008). Stomatal movements and long-distance signaling in plants. Plant Signal. Behav. 3, 772-777. doi: 10.4161/psb.3.10.6294

Jones, H. G. (1977). Transpiration in barley lines with differing stomatal frequencies. J. Exp. Bot. 28, 162-168. doi: 10.1093/jxb/28.1.162

Jones, H. G. (1987). "Breeding for stomatal characters," in Stomatal Function, eds E. Zeiger, G. D. Farquhar, and I. R. Cowan (Stanford, CA: Stanford University Press), 431-443.

Jones, H. G. (2007). Monitoring plant and soil water status: established and novel methods revisited and their relevance to studies of drought tolerance. J. Exp. Bot. 58, 119-130. doi: 10.1093/jxb/erl118

Jones, H. G. (2014). Plants and Microclimate: A Quantitative Approach to Environmental Plant Physiology. Cambridge: Cambridge University Press.

Jones, H. G., and Corlett, J. E. (1992). Current topics in drought physiology. J. Agric. Sci. 119, 291-296. doi: 10.1017/S0021859600012144

Jones, H. G., Serraj, R., Loveys, B. R., Xiong, L., Wheaton, A., and Price, A. H. (2009). Thermal infrared imaging of crop canopies for the remote diagnosis 
and quantification of plant responses to water stress in the field. Funct. Plant Biol. 36, 978-989. doi: 10.1071/FP09123

Karafyllidis, D., Stavropoulos, N., and Georgakis, D. (1996). The effect of water stress on the yielding capacity of potato crops and subsequent performance of seed tubers. Potato Res. 39, 153-163. doi: 10.1007/BF02358215

Karam, F., Hamdy, A., Katerji, N., and Mastrorilli, M. (1996). “Solanum tuberosum water status and yield as affected by salinity and soil texture," in II International Symposium on Irrigation of Horticultural Crops, Vol. 449 (Chania; Crete: ISHS), 635-640.

Karamanos, A. J., and Papatheohari, A. Y. (1999). Assessment of drought resistance of crop genotypes by means of the water potential index. Crop Sci. 39, 1792-1797. doi: 10.2135/cropsci1999.3961792x

Katerji, N., and Mastrorilli, M. (2009). The effect of soil texture on the water use efficiency of irrigated crops: results of a multi-year experiment carried out in the Mediterranean region. Eur. J. Agron. 30, 95-100. doi: 10.1016/j.eja.2008. 07.009

Kerstiens, G. (2006). Water transport in plant cuticles: an update. J. Exp. Bot. 57, 2493-2499. doi: 10.1093/jxb/erl017

Kierzkowski, D., Kmieciak, M., Piontek, P., Wojtaszek, P., Szweykowska-Kulinska, Z., and Jarmolowski, A. (2009). The Arabidopsis CBP20 targets the cap-binding complex to the nucleus, and is stabilized by CBP80. Plant J. 59, 813-823. doi: 10.1111/j.1365-313X.2009.03915.x

Kondrak, M., Marincs, F., Antal, F., Juhasz, Z., and Banfalvi, Z. (2012). Effects of yeast trehalose-6-phosphate synthase 1 on gene expression and carbohydrate contents of potato leaves under drought stress conditions. BMC Plant Biol. 12:74. doi: 10.1186/1471-2229-12-74

Kondrak, M., Marincs, F., Kalapos, B., Juhasz, Z., and Banfalvi, Z. (2011). Transcriptome analysis of potato leaves expressing the trehalose6-phosphate synthase 1 gene of yeast. PLoS ONE 6:e23466. doi: 10.1371/journal.pone.0023466

Körner, C. (2003). Limitation and stress-always or never? J. Veg. Sci. 14, 141-143. doi: 10.1111/j.1654-1103.2003.tb02138.x

Ku, S.-B., Edwards, G. E., and Tanner, C. B. (1977). Effects of light, carbon dioxide, and temperature on photosynthesis, oxygen inhibition of photosynthesis, and transpiration in Solanum tuberosum. Plant Physiol. 59, 868-872. doi: 10.1104/pp.59.5.868

Lahlou, O., and Ledent, J. F. (2005). Root mass and depth, stolons and roots formed on stolons in four cultivars of potato under water stress. Eur. J. Agron. 22, 159-173. doi: 10.1016/j.eja.2004.02.004

Lahlou, O., Ouattar, S., and Ledent, J. F. (2003). The effect of drought and cultivar on growth parameters, yield and yield components of potato. Agronomie 23, 257-268. doi: 10.1051/agro:2002089

Larcher, W. (2000). Temperature stress and survival ability of Mediterranean sclerophyllous plants. Plant Biosyst. 134, 279-295. doi: 10.1080/11263500012331350455

Lawlor, D. W. (2002). Limitation to photosynthesis in water-stressed leaves: stomata vs. metabolism and the role of ATP. Ann. Bot. 89, 871-885. doi: $10.1093 / \mathrm{aob} / \mathrm{mcf} 110$

Lee, H. Y., Seo, J.-S., Cho, J. H., Jung, H., Kim, J.-K., Lee, J. S., et al. (2013). Oryza sativa COI homologues restore jasmonate signal transduction in Arabidopsis coi1-1 Mutants. PLoS ONE 8:e52802. doi: 10.1371/journal.pone.0052802

Lee, J. S. (2010). Stomatal opening mechanism of CAM plants. J. Plant Biol. 53, 19-23. doi: 10.1007/s12374-010-9097-8

Lefevre, I., Ziebel, J., Guignard, C., Hausman, J. F., Gutierrez Rosales, R. O., Bonierbale, M., et al. (2012). Drought impacts mineral contents in andean potato cultivars. J. Agron. Crop Sci. 198, 196-206. doi: 10.1111/j.1439037x.2011.00499.x

Legay, S., Lefevre, I., Lamoureux, D., Barreda, C., Luz, R. T., Gutierrez, R., et al. (2011). Carbohydrate metabolism and cell protection mechanisms differentiate drought tolerance and sensitivity in advanced potato clones (Solanum tuberosum L.). Funct. Integr. Genomics 11, 275-291. doi: 10.1007/s10142-0100206-z

Leinonen, I., and Jones, H. G. (2004). Combining thermal and visible imagery for estimating canopy temperature and identifying plant stress. J. Exp. Bot. 55, 1423-1431. doi: 10.1093/jxb/erh146

Leinonen, I., Grant, O. M., Tagliavia, C. P. P., Chaves, M. M., and Jones, H. G. (2006). Estimating stomatal conductance with thermal imagery. Plant Cell Environ. 29, 1508-1518. doi: 10.1111/j.1365-3040.2006.01528.x
Leone, A., Costa, A., Tucci, M., and Grillo, S. (1994). Comparative-analysis of short-term and long-term changes in gene-expression caused by low water potential in potato (Solanum tuberosum) cell-suspension cultures. Plant Physiol. 106, 703-712.

Levitt, J. (1980). Responses of Plants to Environmental Stresses. Vol. 2. Water, Radiation, Salt, and Other Stresses. New York, NY: Academic Press.

Levy, D. (1983). Varietal differences in the response of potatoes to repeated short periods of water stress in hot climates. 2. Tuber yield and dry matter accumulation and other tuber properties. Potato Res. 26, 315-321. doi: 10.1007/BF02356153

Levy, D. (1985). The response of potatoes to a single transient heat or drought stress imposed at different stages of tuber growth. Potato Res. 28, 415-424. doi: 10.1007/BF02357516

Liu, C. C., Liu, Y. G., Guo, K., Zheng, Y. R., Li, G. Q., Yu, L. F., et al. (2010). Influence of drought intensity on the response of six woody karst species subjected to successive cycles of drought and rewatering. Physiol. Plant. 139, 39-54. doi: 10.1111/j.1399-3054.2009.01341.x

Liu, F. L., Jensen, C. R., Shahanzari, A., Andersen, M. N., and Jacobsen, S. E. (2005). ABA regulated stomatal control and photosynthetic water use efficiency of potato (Solanum tuberosum L.) during progressive soil drying. Plant Sci. 168, 831-836. doi: 10.1016/j.plantsci.2004.10.016

Long, S. P., Humphries, S., and Falkowski, P. G. (1994). Photoinhibition of Photosynthesis in Nature. Annu. Rev. Plant Physiol. Plant Mol. Biol. 45, 633-662. doi: 10.1146/annurev.pp.45.060194.003221

Lopez, C. G., Banowetz, G. M., Peterson, C. J., and Kronstad, W. E. (2003). Dehydrin expression and drought tolerance in seven wheat cultivars. Crop Sci. 43, 577-582. doi: 10.2135/cropsci2003.0577

Ludlow, M. M. (1989). "Strategies of response to water-stress," in Structural and Functional Responses to Environmental Stresses: Water Shortage, eds K. H. Kreeb, H. Richter, and T. M. Hinckley (The Hague: SPB Academic Publishing), 269-281.

Ludlow, M. M., and Muchow, R. C. (1990). A critical-evaluation of traits for improving crop yields in water-limited environments. Adv. Agron. 43, 107-153. doi: 10.1016/S0065-2113(08)60477-0

Luis Araus, J., and Cairns, J. E. (2014). Field high-throughput phenotyping: the new crop breeding frontier. Trends Plant Sci. 19, 52-61. doi: 10.1016/j.tplants.2013.09.008

Lutaladio, N., and Castaidi, L. (2009). Potato: the hidden treasure. J. Food Composit. Anal. 22, 491-493. doi: 10.1016/j.jfca.2009.05.002

Lynch, D. R., and Tai, G. C. C. (1989). Yield and yield component response of eight potato genotypes to water stress. Crop Sci. 29, 1207-1211. doi: 10.2135/cropsci1989.0011183X002900050024x

Mackerron, D. K. L., and Peng, Z. Y. (1989). Genotypic comparisons of potato root growth and yield in response to drought. Aspects Appl. Biol. 22, 199-206.

Mackerron, D., and Jefferies, R. (1986). The influence of early soil moisture stress on tuber numbers in potato. Potato Res. 29, 299-312. doi: 10.1007/BF02359959

Mackerron, D., and Jefferies, R. (1988). The distributions of tuber sizes in droughted and irrigated crops of potato. I. Observations on the effect of water stress on graded yields from differing cultivars. Potato Res. 31, 269-278. doi: 10.1007/BF02365535

Mafakheri, A., Siosemardeh, A., Bahramnejad, B., Struik, P., and Sohrabi, Y. (2010). Effect of drought stress on yield, proline and chlorophyll contents in three chickpea cultivars. Aust. J. Crop Sci. 4, 580-585.

Mahan, J. R., McMichael, B. L., and Wanjura, D. F. (1995). Methods for reducing the adverse effects of temperature stress on plants: a review. Environ. Exp. Bot. 35, 251-258. doi: 10.1016/0098-8472(95)00011-6

Mahlein, A. K., Oerke, E. C., Steiner, U., and Dehne, H. W. (2012). Recent advances in sensing plant diseases for precision crop protection. Eur. J. Plant Pathol. 133, 197-209. doi: 10.1007/s10658-011-9878-z

Manavalan, L. P., Guttikonda, S. K., Tran, L.-S. P., and Nguyen, H. T. (2009). Physiological and molecular approaches to improve drought resistance in soybean. Plant Cell Physiol. 50, 1260-1276. doi: 10.1093/pcp/pcp082

Mane, S. P., Robinet, C. V., Ulanov, A., Schafleitner, R., Tincopa, L., Gaudin, A., et al. (2008). Molecular and physiological adaptation to prolonged drought stress in the leaves of two Andean potato genotypes. Funct. Plant Biol. 35, 669-688. doi: 10.1071/FP07293

Marasco, R., Rolli, E., Ettoumi, B., Vigani, G., Mapelli, F., Borin, S., et al. (2012). A drought resistance-promoting microbiome is selected by root 
system under desert farming. PLoS ONE 7:e48479. doi: 10.1371/journal.pone. 0048479

Maroco, J. P., Edwards, M. S. B., and Edwards, G. E. (2000). Utilization of O-2 in the metabolic optimization of C-4 photosynthesis. Plant Cell Environ. 23, 115-121. doi: 10.1046/j.1365-3040.2000.00531.x

Martin, B., and Ruiztorres, N. A. (1992). Effects of water-deficit stress on photosynthesis, its components and component limitations, and on wateruse efficiency in wheat (triticum-aestivum 1). Plant Physiol. 100, 733-739. doi: 10.1104/pp.100.2.733

Martin, B., and Thorstenson, Y. R. (1988). Stable carbon isotope composition (delta-c-13), water-use efficiency, and biomass productivity of Lycopersicon esculentum, Lycopersicon-pennellii, and the f1-hybrid. Plant Physiol. 88, 213-217. doi: 10.1104/pp.88.1.213

Martin, R. J., Jamieson, P. D., Wilson, D. R., and Francis, G. S. (1992). Effects of soil moisture deficits on yield and quality of russet burbank potatoes. N.Z. J. Crop Hortic. Sci. 20, 1-9. doi: 10.1080/01140671.1992.10422319

Masle, J., Gilmore, S. R., and Farquhar, G. D. (2005). The ERECTA gene regulates plant transpiration efficiency in Arabidopsis. Nature 436, 866-870. doi: $10.1038 /$ nature03835

Massa, A. N., Childs, K. L., and Buell, C. R. (2013). Abiotic and biotic stress responses in Solanum tuberosum group Phureja DM1-3 516 R44 as measured through whole transcriptome sequencing. Plant Genome 6, 15-24. doi: 10.3835/plantgenome2013.05.0014

Maxwell, K., and Johnson, G. N. (2000). Chlorophyll fluorescence-a practical guide. J. Exp. Bot. 51, 659-668. doi: 10.1093/jexbot/51.345.659

McCann, S. E., and Huang, B. (2008). Evaluation of drought tolerance and avoidance traits for six creeping bentgrass cultivars. HortScience 43, 519-524.

McClean, P. E., Burridge, J., Beebe, S., Rao, I. M., and Porch, T. G. (2011). Crop improvement in the era of climate change: an integrated, multi-disciplinary approach for common bean (Phaseolus vulgaris). Funct. Plant Biol. 38, 927-933. doi: $10.1071 / \mathrm{FP} 11102$

Metz, B., Davidson, O., Bosch, P., Dave, R., and Meyer, L. (2007). Mitigation of Climate Change. Cambridge: Cambridge University Press.

Miller, D. E., and Martin, M. W. (1987). Effect of declining or interrupted irrigation on yield and quality of three potato cultivars grown on sandy soil. Am. Potato J. 64, 109-117. doi: 10.1007/BF02854207

Mitchell, J. H., Fukai, S., and Cooper, M. (1996). Influence of phenology on grain yield variation among barley cultivars grown under terminal drought. Aust. J. Agric. Res. 47, 757-774. doi: 10.1071/AR9960757

Mitra, J. (2001). Genetics and genetic improvement of drought resistance in crop plants. Curr. Sci. 80, 758-763.

Mittler, R. (2006). Abiotic stress, the field environment and stress combination. Trends Plant Sci. 11, 15-19. doi: 10.1016/j.tplants.2005.11.002

Moorby, J., Munns, R., and Walcott, J. (1975). Effect of water deficit on photosynthesis and tuber metabolism in potatoes. Aust. J. Plant Physiol. 2, 323-333. doi: 10.1071/PP9750323

Morgan, J. M. (1984). Osmoregulation and water stress in higher plants. Annu. Rev. Plant Physiol. Plant Mol. Biol. 35, 299-319. doi: 10.1146/annurev.pp.35.060184.001503

Mullins, E., Milbourne, D., Petti, C., Doyle-Prestwich, B. M., and Meade, C. (2006). Potato in the age of biotechnology. Trends Plant Sci. 11, 254-260. doi: 10.1016/j.tplants.2006.03.002

Mutava, R. N., Prasad, P. V. V., Tuinstra, M. R., Kofoid, M. D., and Yu, J. (2011). Characterization of sorghum genotypes for traits related to drought tolerance. Field Crops Res. 123, 10-18. doi: 10.1016/j.fcr.2011.04.006

Nadler, A., and Heuer, B. (1995). Effect of saline irrigation and water deficit on tuber quality. Potato Res. 38, 119-123. doi: 10.1007/BF02358078

Naher, U. A., Othman, R., and Panhwar, Q. A. (2013). Beneficial effects of mycorrhizal association for crop production in the tropics-a review. Int. J. Agric. Biol. 15, 1021-1028.

Naveed, M., Mitter, B., Reichenauer, T. G., Wieczorek, K., and Sessitsch, A. (2014). Increased drought stress resilience of maize through endophytic colonization by Burkholderia phytofirmans PsJN and Enterobacter sp FD17. Environ. Exp. Bot. 97, 30-39. doi: 10.1016/j.envexpbot.2013.09.014

Nejad, A. R., and Van Meeteren, U. (2007). The role of abscisic acid in disturbed stomatal response characteristics of Tradescantia virginiana during growth at high relative air humidity. J. Exp. Bot. 58, 627-636. doi: 10.1093/jxb/ erl234
Neumann, P. M. (2008). Coping mechanisms for crop plants in drought-prone environments. Ann. Bot. 101, 901-907. doi: 10.1093/aob/mcn018

Newell, L. L., Garner, J. O., and Silva, J. L. (1994). Estimation of drought tolerance in sweet-potatoes. Phyton Int. J. Exp. Bot. 56, 119-125.

Nguyen, T. T. T., Klueva, N., Chamareck, V., Aarti, A., Magpantay, G., Millena, A. C. M., et al. (2004). Saturation mapping of QTL regions and identification of putative candidate genes for drought tolerance in rice. Mol. Genet. Genomics 272, 35-46. doi: 10.1007/s00438-004-1025-5

NOAA. (2011). National Oceanic and Atmospheric Administration Report. Washington, DC: United States Department of Commerce.

NOAA. (2012). National Oceanic and Atmospheric Administration Report. Washington, DC: United States Department of Commerce.

Okamoto, M., Peterson, F. C., Defries, A., Park, S.-Y., Endo, A., Nambara, E., et al. (2013). Activation of dimeric ABA receptors elicits guard cell closure, ABAregulated gene expression, and drought tolerance. Proc. Natl. Acad. Sci. U.S.A. 110, 12132-12137. doi: 10.1073/pnas.1305919110

Okogbenin, E., Setter, T. L., Ferguson, M., Mutegi, R., Ceballos, H., Olasanmi, B., et al. (2013). Phenotypic approaches to drought in cassava: review. Front. Physiol. 4:93. doi: 10.3389/fphys.2013.00093

Onder, S., Caliskan, M. E., Onder, D., and Caliskan, S. (2005). Different irrigation methods and water stress effects on potato yield and yield components. Agric. Water Manag. 73, 73-86. doi: 10.1016/j.agwat.2004.09.023

O'Neill, P. M., Shanahan, J. E., and Schepers, J. S. (2006). Use of chlorophyll fluorescence assessments to differentiate corn hybrid response to variable water conditions. Crop Sci. 46, 681-687. doi: 10.2135/cropsci2005.06-0170

Pal, A. K., Acharya, K., Vats, S. K., Kumar, S., and Ahuja, P. S. (2013). Over-expression of PaSOD in transgenic potato enhances photosynthetic performance under drought. Biol. Plant. 57, 359-364. doi: 10.1007/s10535-0120277-x

Papp, I., Mur, L. A., Dalmadi, A., Dulai, S., and Koncz, C. (2004). A mutation in the Cap Binding Protein 20 gene confers drought tolerance to Arabidopsis. Plant Mol. Biol. 55, 679-686. doi: 10.1007/s11103-004-1680-2

Parry, M. A., Andralojc, P. J., Scales, J. C., Salvucci, M. E., Carmo-Silva, A. E., Alonso, H., et al. (2013). Rubisco activity and regulation as targets for crop improvement. J. Exp. Bot. 64, 717-730. doi: 10.1093/jxb/ers336

Passioura, J. B. (1996). Drought and drought tolerance. Plant Growth Regul. 20, 79-83. doi: 10.1007/BF00024003

Paulus, S., Behmann, J., Mahlein, A.-K., Plümer, L., and Kuhlmann, H. (2014). Low-cost 3D systems: suitable tools for plant phenotyping. Sensors 14, 3001-3018. doi: 10.3390/s140203001

Pieczynski, M., Marczewski, W., Hennig, J., Dolata, J., Bielewicz, D., Piontek, P., et al. (2013). Down-regulation of CBP80 gene expression as a strategy to engineer a drought-tolerant potato. Plant Biotechnol. J. 11, 459-469. doi: 10.1111/pbi.12032

Pinheiro, C., and Chaves, M. M. (2011). Photosynthesis and drought: can we make metabolic connections from available data? J. Exp. Bot. 62, 869-882. doi: 10.1093/jxb/erq340

Pinter, J. P. J., Zipoli, G., Reginato, R. J., Jackson, R. D., Idso, S. B., and Hohman, J. P. (1990). Canopy temperature as an indicator of differential water use and yield performance among wheat cultivars. Agric. Water Manag. 18, 35-48. doi: 10.1016/0378-3774(90)90034-V

Porter, G. A., Opena, G. B., Bradbury, W. B., McBurnie, J. C., and Sisson, J. A. (1999). Soil management and supplemental irrigation effects on potato: I. Soil properties, tuber yield, and quality. Agron. J. 91, 416-425. doi: 10.2134/agronj1999.00021962009100030010x

Porter, J. R., and Semenov, M. A. (2005). Crop responses to climatic variation. Philos. Trans. R. Soc. B Biol. Sci. 360, 2021-2035. doi: 10.1098/rstb.2005.1752

Prashar, A., and Jones, H. G. (2014). Infra-red thermography as a highthroughput tool for field phenotyping. Agronomy 4, 397-417. doi: 10.3390/agronomy4030397

Prashar, A., Yildiz, J., McNicol, J. W., Bryan, G. J., and Jones, H. G. (2013). Infra-red thermography for high throughput field phenotyping in Solanum tuberosum. PLoS ONE 8:e65816. doi: 10.1371/journal.pone.0065816

Proietti, S., Moscatello, S., Battistelli, A., Mauromicale, G., and Ierna, A. (2005). Quality of early potato in Sicily as affected by cultivar, sowing time and irrigation. Acta Hortic. 684, 171-176.

Puértolas, J., Ballester, C., Elphinstone, E. D., and Dodd, I. C. (2014). Two potato (Solanum tuberosum) varieties differ in drought tolerance due to differences 
in root growth at depth. Funct. Plant Biol. 41, 1107-1118. doi: 10.1071/ FP14105

Qifu, M., and Murray, F. (1991). Responses of potato plants to sulfurdioxide, water-stress and their combination. New Phytol. 118, 101-109. doi: 10.1111/j.1469-8137.1991.tb00570.x

Ranalli, P., Dicandilo, M., and Bagatta, M. (1997). Drought tolerance screening for potato improvement. Plant Breed. 116, 290-292. doi: 10.1111/j.14390523.1997.tb00999.x

Rebetzke, G. J., and Richards, R. A. (1999). Genetic improvement of early vigour in wheat. Aust. J. Agric. Res. 50, 291-301. doi: 10.1071/A98125

Rebetzke, G. J., Condon, A. G., Richards, R. A., and Farquhar, G. D. (2002). Selection for reduced carbon isotope discrimination increases aerial biomass and grain yield of rainfed bread wheat. Crop Sci. 42, 739-745. doi: $10.2135 /$ cropsci2002.0739

Rebetzke, G. J., Rattey, A. R., Farquhar, G. D., Richards, R. A., and Condon, A. G. (2013). Genomic regions for canopy temperature and their genetic association with stomatal conductance and grain yield in wheat. Funct. Plant Biol. 40, 14-33. doi: 10.1071/FP12184

Reiter, W. D., and Vanzin, G. F. (2001). Molecular genetics of nucleotide sugar interconversion pathways in plants. Plant Mol. Biol. 47, 95-113. doi: 10.1023/A:1010671129803

Rensink, W. A., Iobst, S., Hart, A., Stegalkina, S., Liu, J., and Buell, C. R. (2005). Gene expression profiling of potato responses to cold, heat, and salt stress. Funct. Integr. Genomics 5, 201-207. doi: 10.1007/s10142-005-0141-6

Richards, R. A. (2006). Physiological traits used in the breeding of new cultivars for water-scarce environments. Agric. Water Manag. 80, 197-211. doi: 10.1016/j.agwat.2005.07.013

Rizhsky, L., Liang, H. J., Shuman, J., Shulaev, V., Davletova, S., and Mittler, R. (2004). When defense pathways collide. The response of Arabidopsis to a combination of drought and heat stress. Plant Physiol. 134, 1683-1696. doi: 10.1104/pp.103.033431

Rowe, R. C., and Powelson, M. L. (2002). Potato early dying: management challenges in a changing production environment. Plant Dis. 86, 1184-1193. doi: 10.1094/PDIS.2002.86.11.1184

Ruiz-Sanchez, M., Armada, E., Munoz, Y., Garcia De Salamone, I. E., Aroca, R., Manuel Ruiz-Lozano, J., et al. (2011). Azospirillum and arbuscular mycorrhizal colonization enhance rice growth and physiological traits under well-watered and drought conditions. J. Plant Physiol. 168, 1031-1037. doi: 10.1016/j.jplph.2010.12.019

Rykaczewska, K. (2013). The impact of high temperature during growing season on potato cultivars with different response to environmental stresses. Am. J. Plant Sci. 4, 2386-2393. doi: 10.4236/ajps.2013.412295

Sadok, W., and Sinclair, T. R. (2011). Crops yield increase under water-limited conditions: review of recent physiological advances for soybean genetic improvement. Adv. Agron. 113, 313-337.

Salinger, M., Sivakumar, M., and Motha, R. (2005). Reducing vulnerability of agriculture and forestry to climate variability and change: workshop summary and recommendations. Clim. Change 70, 341-362. doi: 10.1007/s10584-0055954-8

Sander, J. D., and Joung, J. K. (2014). CRISPR-Cas systems for editing, regulating and targeting genomes. Nat. Biotechnol. 32, 347-355. doi: 10.1038/nbt.2842

Sanders, D., Pelloux, J., Brownlee, C., and Harper, J. F. (2002). Calcium at the crossroads of signaling. Plant Cell 14, S401-S417. doi: 10.1105/tpc.002899

Sanders, G., and Arndt, S. (2012). “Osmotic adjustment under drought conditions," in Plant Responses to Drought Stress, ed R. Aroca (Berlin; Heidelberg: Springer), 199-229. doi: 10.1007/978-3-642-32653-0_8

Schafleitner, R., Gaudin, A., Rosales, R. O. G., Aliaga, C. A. A., and Bonierbale, M. (2007a). Proline accumulation and real time PCR expression analysis of genes encoding enzymes of proline metabolism in relation to drought tolerance in Andean potato. Acta Physiol. Plant. 29, 19-26. doi: 10.1007/s11738-0060003-4

Schafleitner, R., Gutierrez, R., Espino, R., Gaudin, A., Perez, J., Martinez, M., et al. (2007b). Field screening for variation of drought tolerance in Solanum tuberosum L. by agronomical, physiological and genetic analysis. Potato Res. 50, 71-85. doi: 10.1007/s11540-007-9030-9

Schafleitner, R., Rosales, R. O. G., Gaudin, A., Aliaga, C. A. A., Martinez, G. N., and Bonierbale, M. $(2007 \mathrm{c})$. Capturing candidate drought tolerance traits in two native Andean potato clones by transcription profiling of field grown plants under water stress. Plant Physiol. Biochem. 45, 673-690. doi: 10.1016/j.plaphy.2007.06.003

Schapendonk, A. H. C. M., Spitters, C. J. T., and Groot, P. J. (1989). Effects of water stress on photosynthesis and chlorophyll fluorescence of five potato cultivars. Potato Res. 32, 17-32. doi: 10.1007/BF02365814

Schittenhelm, S., Sourell, H., and Lopmeier, F. J. (2006). Drought resistance of potato cultivars with contrasting canopy architecture. Eur. J. Agron. 24, 193-202. doi: 10.1016/j.eja.2005.05.004

Schulze, E. D., and Hall, A. E. (1982). "Stomatal responses, water loss and CO2 assimilation rates of plants in contrasting environments," in Physiological Plant Ecology II, eds O. L. Lange, P. S. Nobel, C. B. Osmond, and H. Ziegler (Berlin; Heidelberg: Springer), 181-230.

Scott, G. J., Rosegrant, M. W., and Ringler, C. (2000). "Roots and Tubers for the 21st Century: Trends, Projections, and Policy Options," in Food, Agriculture and the Environment Discussion Paper (Washington, DC: International Food Policy Research Institute).

Serraj, R., Krishnamurthy, L., Kashiwagi, J., Kumar, J., Chandra, S., and Crouch, J. H. (2004). Variation in root traits of chickpea (Cicer arietinum L.) grown under terminal drought. Field Crops Res. 88, 115-127. doi: 10.1016/j.fcr.2003.12.001

Sharma, S., Upadhyaya, H. D., Varshney, R. K., and Gowda, C. (2013). Pre-breeding for diversification of primary gene pool and genetic enhancement of grain legumes. Front. Plant Sci. 4:309. doi: 10.3389/fpls.2013.00309

Sharma, S., Villamor, J. G., and Verslues, P. E. (2011). Essential role of tissuespecific proline synthesis and catabolism in growth and redox balance at low water potential. Plant Physiol. 157, 292-304. doi: 10.1104/pp.111.183210

Shin, D., Moon, S.-J., Han, S., Kim, B.-G., Park, S. R., Lee, S.-K., et al. (2011). Expression of StMYB1R-1, a novel potato single MYB-like domain transcription factor, increases drought tolerance. Plant Physiol. 155, 421-432. doi: $10.1104 / \mathrm{pp} .110 .163634$

Shiri-E-Janagard, M., Tobeh, A., Abbasi, A., Jamaati-E-Somarin, S., Hassanzadeh, M., and Zabihi-E-Mahmoodabad, R. (2009). Effects of water stress on water demand, growth and tuber grade of potato (Solanum tuberosum L.) crop. Res. J. Environ. Sci. 3, 476-485. doi: 10.3923/rjes.2009.476.485

Shock, C. C., Feibert, E. B. G., and Saunders, L. D. (1998). Potato yield and quality response to deficit irrigation. HortScience 33, 655-659.

Shock, C. C., Holmes, Z. A., Stieber, T. D., Eldredge, E. P., and Zhang, P. (1993). The effect of timed water stress on quality, total solids and reducing sugar content of potatoes. Am. Potato J. 70, 227-241. doi: 10.1007/BF02849311

Shock, C., Feibert, E., Saunders, L., and James, S. (2003). 'Umatilla Russet' and 'Russet Legend' potato yield and quality response to irrigation. HortScience 38, 1117-1121.

Shock, C., Zalewski, J., Stieber, T., and Burnett, D. (1992). Impact of early-season water deficits on Russet Burbank plant development, tuber yield and quality. Am. Potato J. 69, 793-803. doi: 10.1007/BF02854186

Skirycz, A., De Bodt, S., Obata, T., De Clercq, I., Claeys, H., De Rycke, R., et al. (2010). Developmental stage specificity and the role of mitochondrial metabolism in the response of Arabidopsis leaves to prolonged mild osmotic stress. Plant Physiol. 152, 226-244. doi: 10.1104/pp.109.148965

Smillie, R. M., and Nott, R. (1982). Salt tolerance in crop plants monitored by chlorophyll fluorescence invivo. Plant Physiol. 70, 1049-1054. doi: 10.1104/pp.70.4.1049

Specht, J. E., Chase, K., Macrander, M., Graef, G. L., Chung, J., Markwell, J. P., et al. (2001). Soybean response to water: a QTL analysis of drought tolerance. Crop Sci. 41, 493-509. doi: 10.2135/cropsci2001.412493x

Sperry, J. S., Hacke, U. G., Oren, R., and Comstock, J. P. (2002). Water deficits and hydraulic limits to leaf water supply. Plant Cell Environ. 25, 251-263. doi: 10.1046/j.0016-8025.2001.00799.x

Spitters, C. J. T., and Schapendonk, A. (1990). Evaluation of breeding strategies for drought tolerance in potato by means of crop growth simulation. Plant Soil 123, 193-203. doi: 10.1007/BF00011268

Spollen, W. G., Sharp, R. E., Saab, I. N., and Wu, Y. (1993). "Water deficits: plant responses from cell to community," in Water Deficits: Plant Responses from Cell to Community, eds J. A. C. Smith and H. Griffiths (Oxford: Bios Scientific Publishers), 37-52.

Stalham, M. A., and Allen, E. J. (2004). Water uptake in the potato (Solanum tuberosum) crop. J. Agric. Sci. 142, 373-393. doi: 10.1017/S0021859604004551

Steckel, J. R. A., and Gray, D. (1979). Drought tolerance in potatoes. J. Agric. Sci. 92, 375-381. doi: 10.1017/S0021859600062900 
Steyn, J. M., Du Plessis, H. F., Fourie, P., and Hammes, P. S. (1998). Yield response of potato genotypes to different soil water regimes in contrasting seasons of a subtropical climate. Potato Res. 41, 239-254. doi: 10.1007/ BF02358194

Stiller, I., Dulai, S., Kodrak, M., Tarnai, R., Szabo, L., Toldi, O., et al. (2008). Effects of drought on water content and photosynthetic parameters in potato plants expressing the trehalose-6-phosphate synthase gene of Saccharomyces cerevisiae. Planta 227, 299-308. doi: 10.1007/s00425-007-0617-9

Szabados, L., and Savouré, A. (2010). Proline: a multifunctional amino acid. Trends Plant Sci. 15, 89-97. doi: 10.1016/j.tplants.2009.11.009

Tambussi, E. A., Bort, J., and Araus, J. L. (2007). Water use efficiency in C3 cereals under Mediterranean conditions: a review of physiological aspects. Ann. Appl. Biol. 150, 307-321. doi: 10.1111/j.1744-7348.2007.00143.x

Tardieu, F. (2012). Any trait or trait-related allele can confer drought tolerance: just design the right drought scenario. J. Exp. Bot. 63, 25-31. doi: 10.1093/jxb/err269

Tardieu, F., and Simonneau, T. (1998). Variability among species of stomatal control under fluctuating soil water status and evaporative demand: modelling isohydric and anisohydric behaviours. J. Exp. Bot. 49, 419-432. doi: 10.1093/jxb/49.Special_Issue.419

Teixeira, J., and Pereira, S. (2007). High salinity and drought act on an organ-dependent manner on potato glutamine synthetase expression and accumulation. Environ. Exp. Bot. 60, 121-126. doi: 10.1016/j.envexpbot.2006.09.003

Teresa Pino, M., Avila, A., Molina, A., Jeknic, Z., and Chen, T. H. H. (2013). Enhanced in vitro drought tolerance of Solanum tuberosum and Solanum commersonii plants overexpressing the ScCBF1 gene. Ciencia E Investigacion Agraria 40, 171-184. doi: 10.4067/S0718-16202013000100015

Tisne, S., Schmalenbach, I., Reymond, M., Dauzat, M., Pervent, M., Vile, D., et al. (2010). Keep on growing under drought: genetic and developmental bases of the response of rosette area using a recombinant inbred line population. Plant Cell Environ. 33, 1875-1887. doi: 10.1111/j.1365-3040.2010.02191.x

Tollenaar, M., and Bruulsema, T. W. (1988). Efficiency of maize dry-matter production during periods of complete leaf-area expansion. Agron. J. 80, 580-585. doi: 10.2134/agronj1988.00021962008000040008x

Tondelli, A., Francia, E., Barabaschi, D., Aprile, A., Skinner, J. S., Stockinger, E. J., et al. (2006). Mapping regulatory genes as candidates for cold and drought stress tolerance in barley. Theor. Appl. Genet. 112, 445-454. doi: 10.1007/s00122-005-0144-7

Topp, C. N., Iyer-Pascuzzi, A. S., Anderson, J. T., Lee, C.-R., Zurek, P. R., Symonova, O., et al. (2013). 3D phenotyping and quantitative trait locus mapping identify core regions of the rice genome controlling root architecture. Proc. Natl. Acad. Sci. U.S.A. 110, E1695-E1704. doi: 10.1073/pnas.1304354110

Tourneux, C., Devaux, A., Camacho, M. R., Mamani, P., and Ledent, J. F. (2003a). Effect of water shortage on six potato genotypes in the highlands of Bolivia (II): water relations, physiological parameters. Agronomie 23, 181-190. doi: 10.1051/agro:2002080

Tourneux, C., Devaux, A., Camacho, M. R., Mamani, P., and Ledent, J. F. (2003b). Effects of water shortage on six potato genotypes in the highlands of Bolivia (I): morphological parameters, growth and yield. Agronomie 23, 169-179. doi: 10.1051/agro:2002079

Trebejo, I., and Midmore, D. J. (1990). Effect of water-stress on potato growth, yield and water-use in a hot and a cool tropical climate. J. Agric. Sci. 114, 321-334. doi: $10.1017 /$ S0021859600072713

Trewavas, A. (2002). Plant cell signal transduction the emerging phenotype. Plant Cell 14, S3-S4. doi: 10.1105/tpc.141360

Tuberosa, R. (2012). Phenotyping for drought tolerance of crops in the genomics era. Front. Physiol. 3:347. doi: 10.3389/fphys.2012.00347

Turner, N. C. (1986). Crop water deficits: a decade of progress. Adv. Agron. 39, 1-51. doi: 10.1016/S0065-2113(08)60464-2

Turner, N. C. (1997). Further progress in crop water relations. Adv. Agron. 58, 293-338. doi: 10.1016/S0065-2113(08)60258-8

Vadez, V. (2014). Root hydraulics: the forgotten side of roots in drought adaptation. Field Crops Res. 165, 15-24. doi: 10.1016/j.fcr.2014.03.017

Van Der Mescht, A., De Ronde, J. A., and Rossouw, F. T. (1999). Chlorophyll fluorescence and chlorophyll content as a measure of drought tolerance in potato. S. Afr. J. Sci. 95, 407-412.

Vanková, R., Dobrá, J., and Štorchová, H. (2012). Recovery from drought stress in tobacco: an active process associated with the reversal of senescence in some plant parts and the sacrifice of others. Plant Signal. Behav. 7, 19-21. doi: $10.4161 /$ psb.7.1.18375

Vasquez-Robinet, C., Mane, S. P., Ulanov, A. V., Watkinson, J. I., Stromberg, V. K., De Koeyer, D., et al. (2008). Physiological and molecular adaptations to drought in Andean potato genotypes. J. Exp. Bot. 59, 2109-2123. doi: 10.1093/jxb/ern073

Verelst, W., Skirycz, A., and Inzé, D. (2010). Abscisic acid, ethylene and gibberellic acid act at different developmental stages to instruct the adaptation of young leaves to stress. Plant Signal. Behav. 5, 473-475. doi: 10.4161/psb.5.4.11421

Vertucci, C. W., Ellenson, J. L., and Leopold, A. C. (1985). Chlorophyll fluorescence characteristics associated with hydration level in pea cotyledons. Plant Physiol. 79, 248-252. doi: 10.1104/pp.79.1.248

Vos, J., and Groenwold, J. (1989). Characteristics of photosynthesis and conductance of potato canopies and the effects of cultivar and transient drought. Field Crops Res. 20, 237-250. doi: 10.1016/0378-4290(89)90068-3

Vos, J., and Oyarzun, P. J. (1987). Photosynthesis and stomatal conductance of potato leaves-effects of leaf age, irradiance, and leaf water potential. Photosyn. Res. 11, 253-264. doi: 10.1007/BF00055065

Wang, H., and Clarke, J. M. (1993). Relationship of excised-leaf water-loss and stomatal frequency in wheat. Can. J. Plant Sci. 73, 93-99. doi: 10.4141/cjps 93-012

Wang, W. X., Vinocur, B., and Altman, A. (2003). Plant responses to drought, salinity and extreme temperatures: towards genetic engineering for stress tolerance. Planta 218, 1-14. doi: 10.1007/s00425-003-1105-5

Wang-Pruski, G., and Schofield, A. (2012). "Potato: improving crop productivity and abiotic stress tolerance," in Improving Crop Resistance to Abiotic Stress, Vol. 1 \& Vol. 2 (Wiley online library), 1121-1153. doi: 10.1002/9783527632930.ch44

Wasternack, C., and Parthier, B. (1997). Jasmonate-signalled plant gene expression. Trends Plant Sci. 2, 302-307. doi: 10.1016/S1360-1385(97)89952-9

Watanabe, K. N., Kikuchi, A., Shimazaki, T., and Asahina, M. (2011). Salt and drought stress tolerances in transgenic potatoes and wild species. Potato Res. 54, 319-324. doi: 10.1007/s11540-011-9198-x

Wegener, C. B., and Jansen, G. (2013). Antioxidants in different potato genotypes: effect of drought and wounding stress. Agriculture 3, 131-146. doi: 10.3390/agriculture 3010131

Weisz, R., Kaminski, J., and Smilowitz, Z. (1994). Water-Deficit effects on Potato leaf growth and transpiration - Utilizing fraction extractable SoilWater for comparison with other crops. Am. Potato J. 71, 829-840. doi: 10.1007/BF02849378

Werner, T., Nehnevajova, E., Koellmer, I., Novak, O., Strnad, M., Kraemer, U., et al. (2010). Root-specific reduction of cytokinin causes enhanced root growth, drought tolerance, and leaf mineral enrichment in arabidopsis and tobacco. Plant Cell 22, 3905-3920. doi: 10.1105/tpc.109.072694

Westgate, M. E., and Boyer, J. S. (1985). Osmotic adjustment and the inhibition of leaf, root, stem and silk growth at low water potentials in maize. Planta 164, 540-549. doi: 10.1007/BF00395973

White, P. J., Bradshaw, J. E., Dale, M. F. B., Ramsay, G., Hammond, J. P., and Broadley, M. R. (2009). Relationships between yield and mineral concentrations in potato tubers. HortScience 44, 6-11.

Wilson, J. R., Ludlow, M. M., Fisher, M. J., and Schulze, E. D. (1980). Adaptation to water stress of the leaf water relations of four tropical forage species. Aust. J. Plant Physiol. 7, 207-220. doi: 10.1071/PP9800207

Win, K., Berkowitz, G. A., and Henninger, M. (1991). Antitranspirant-induced increases in leaf water potential increase tuber calcium and decrease tuber necrosis in water-stressed potato plants. Plant Physiol. 96, 116-120. doi: 10.1104/pp.96.1.116

Wishart, J., George, T. S., Brown, L. K., Ramsay, G., Bradshaw, J. E., White, P. J., et al. (2013). Measuring variation in potato roots in both field and glasshouse: the search for useful yield predictors and a simple screen for root traits. Plant Soil 368, 231-249. doi: 10.1007/s11104-012-1483-1

Wolfe, D. W., Fereres, E., and Voss, R. E. (1983). Growth and yield response of two potato cultivars to various levels of applied water. Irrigation Sci. 3, 211-222. doi: 10.1007/BF00272837

Wurr, D. C. E. (1978). “Seed production and management," in The Potato Crop, ed P. M. Harris (London: Chapman and Hall), 327-354.

Xu, F., Guo, W., Xu, W., Wei, Y., and Wang, R. (2009). Leaf morphology correlates with water and light availability: what consequences for simple and compound leaves? Prog. Nat. Sci. 19, 1789-1798. doi: 10.1016/j.pnsc.2009.10.001 
Xu, L.-K., and Hsiao, T. C. (2004). Predicted versus measured photosynthetic water-use efficiency of crop stands under dynamically changing field environments. J. Exp. Bot. 55, 2395-2411. doi: 10.1093/jxb/erh271

Xu, Z., Zhou, G., and Shimizu, H. (2010). Plant responses to drought and rewatering. Plant Signal. Behav. 5, 649-654. doi: 10.4161/psb.5.6.11398

Yu, L., Chen, X., Wang, Z., Wang, S., Wang, Y., Zhu, Q., et al. (2013). Arabidopsis enhanced drought tolerance1/HOMEODOMAIN GLABROUS11 confers drought tolerance in transgenic rice without yield penalty. Plant Physiol. 162, 1378-1391. doi: 10.1104/pp.113.217596

Zhang, N., Liu, B., Ma, C., Zhang, G., Chang, J., Si, H., et al. (2014). Transcriptome characterization and sequencing-based identification of drought-responsive genes in potato. Mol. Biol. Rep. 41, 505-517. doi: 10.1007/s11033-013-2886-7

Zhang, N., Si, H.-J., Wen, G., Du, H.-H., Liu, B.-L., and Wang, D. (2011). Enhanced drought and salinity tolerance in transgenic potato plants with a $\mathrm{BADH}$ gene from spinach. Plant Biotechnol. Rep. 5, 71-77. doi: 10.1007/s11816-010-0160-1

Zhang, R., Marshall, D., Bryan, G. J., and Hornyik, C. (2013). Identification and characterization of miRNA transcriptome in potato by high-throughput sequencing. PLoS ONE 8:e57233. doi: 10.1371/journal.pone.0057233
Zia, S., Romano, G., Spreer, W., Sanchez, C., Cairns, J., Araus, J. L., et al. (2013). Infrared thermal imaging as a rapid tool for identifying water-stress tolerant maize genotypes of different phenology. J. Agron. Crop Sci. 199, 75-84. doi: 10.1111/j.1439-037X.2012.00537.x

Zrùst, J., Vacek, K., Hála, J., Janáèková, I., Adamec, F., Ambrož, M., et al. (1994). Influence of water stress on photosynthesis and variable chlorophyll fluorescence of potato leaves. Biol. Plant. 36, 209-214. doi: 10.1007/BF02921088

Conflict of Interest Statement: The authors declare that the research was conducted in the absence of any commercial or financial relationships that could be construed as a potential conflict of interest.

Copyright (c) 2015 Obidiegwu, Bryan, Jones and Prashar. This is an open-access article distributed under the terms of the Creative Commons Attribution License (CC $B Y)$. The use, distribution or reproduction in other forums is permitted, provided the original author(s) or licensor are credited and that the original publication in this journal is cited, in accordance with accepted academic practice. No use, distribution or reproduction is permitted which does not comply with these terms. 